\title{
Ciclo político presupuestal y gobiernos con y sin mayoría en México, 1994 y 2006
}

\section{Political budget cycle under divided and unified government in Mexico, 1994 and 2006}

\author{
Marlen R. Reyes-Hernández* \\ Pablo MejÍA-Reyes** \\ PaOlo Riguzzi ${ }^{* * *}$
}

\begin{abstract}
In order to substantiate the evidence of political budget cycle (PBC) in Mexico, this essay examines the federal budget before and after the presidential elections of 1994 and 2006. Previous studies are extended since we incorporate the effects of unified or divided government on the budget-making process, focusing on the relationship between the Chamber of Deputies and the Executive. The essay analyzes how and to which extent the Deputies reapportioned the budget plan submitted by the President, as well as the evidence of $P B C$ based on the difference between authorized and actual federal spending. We find that under a unified government the composition of the Chamber of Deputies encourages PBC; whereas, under a divided government, it cannot prevent it altogether.
\end{abstract}

Keywords: political budget cycle, federal budget, public expenditure, Mexico.

\section{Resumen}

En este documento se analiza el gasto público federal ejercido antes y después de las elecciones presidenciales de 1994 y 2006 en México, para identificar la existencia de un ciclo político-presupuestal (CPP). Se extienden los estudios previos al incorporar los efectos de la existencia o no de mayoría del partido del presidente en la Cámara de Diputados en la determinación del presupuesto de egresos. Específicamente, se examinan las reasignaciones que la Cámara de Diputados ha realizado al proyecto de presupuesto enviado por el Ejecutivo federal, así como la presencia de ciclos presupuestales en el gasto propuesto y ejercido por el Ejecutivo y aprobado por la misma Cámara. Se encontró que en un gobierno con mayoría, la composición de la Cámara de Diputados facilita la configuración de un CPP, en tanto que uno sin mayoría no puede evitarlo plenamente.

Palabras clave: ciclo político presupuestal, presupuesto, gasto público, México.

* Campus Universitario Siglo XXI, México. Correo-e: doc.rhmar@cus21.edu.mx.

** Universidad Autónoma del Estado de México, México. Correo-e: pmejiare@uaemex.mx.

*** El Colegio Mexiquense, A.c. Correo-e: priguzzi@cmq.edu.mx. 


\section{Introducción}

A partir del enfoque macroeconómico tradicional se considera a toda acción del gobierno, dirigida a influir en la trayectoria temporal de alguna variable económica, como política económica. Dicha política se dirige a la consecución de objetivos macroeconómicos -como eficacia productiva, equidad distributiva y estabilidad y sostenibilidad del crecimiento, entre otros- para evitar o corregir aquellos desequilibrios que, si crecen o perduran en el tiempo, pueden hacer imposible alcanzar dichos fines (Argandoña, 1996). En esta perspectiva, se percibe al gobierno como un ente benévolo que sabe lo que desean y necesitan los gobernados e intenta conseguirlo en aras de la maximización del bienestar social. Sin embargo, no es difícil suponer que los gobernantes pueden tener otros fines, como conservar el poder, la reelección, el aumento de ingresos propios, el prestigio y la puesta en práctica de una ideología, entre otros. Así, es posible que a las explicaciones teóricas sobre las causas de los ciclos económicos se sumen las de naturaleza política. En este marco es oportuno introducir las categorías de ciclo político económico ( $\mathrm{CPE}$ ) y ciclo político presupuestal (CPP) que la literatura ha desarrollado para dar cuenta de la manipulación de las políticas económicas y, en especial, fiscales por parte de los gobiernos con fines electorales y tintes oportunistas. La primera de ellas se originó en los años setenta, mientras que la segunda constituye una derivación más reciente. En esencia, Shi y Svensson definen el CPP como "la fluctuación periódica en las políticas fiscales del gobierno, inducidas por el calendario electoral" (2002: 1).

En el caso de México, existe una percepción generalizada sobre el manejo político de los instrumentos de política económica (Heath, 2000). En perspectiva histórica, comenzando con el esquema de industrialización con sustitución de importaciones -aplicado desde la década de los años cuarenta- hasta el modelo de economía abierta actual, se observan una serie de inconsistencias o desviaciones coyunturales en la aplicación de la política económica, que parecen responder, en buena medida, a razones políticas más que a circunstancias particulares o a errores involuntarios de los responsables de poner en práctica las medidas económicas (Magaloni, 2000). En ese sentido, es razonable plantear la pregunta de si las autoridades mexicanas han manejado el gasto público con fines electorales de manera sistemática.

Un tema tan importante ha captado la atención de varios estudiosos que han tratado de documentar la evidencia de CPE y de CPP en el caso de México. Gámez y Botello (1987) encontraron evidencia de que, durante el periodo 1953-1982, el ciclo presidencial ejerció influencia significativa en el comportamiento del gasto público, las exportaciones y el 
ingreso agregado. Magaloni (2000), a su vez, analizó la influencia del ciclo político en la economía mexicana entre 1970 y 1998, y encontró incrementos en el gasto público, el consumo privado y el crecimiento de la economía antes de las elecciones, una postergación estratégica de los ajustes cambiarios hasta después de los procesos electorales, así como una contracción de la actividad económica después de los comicios.

Por otro lado, en lo referente al cPp, González (2002) estudió el periodo 1957-1997 y encontró evidencia de manipulación de instrumentos de política fiscal en las etapas preelectorales, particularmente en el tamańo del gasto público y ciertas partidas del mismo, como la inversión pública y los pagos de transferencia.

Estos estudios, sin embargo, se han enfocado casi exclusivamente en el papel del Poder Ejecutivo como actor político central, ${ }^{1}$ aun cuando algunos autores han señalado que entre las razones que favorecen el manejo oportunista de los instrumentos de política fiscal se encuentra el grado de control que el gobierno tenga sobre los diversos instrumentos de política, especialmente del gasto público, lo cual se ve favorecido por la existencia de sistemas institucionales de contrapesos débiles (Drazen, 2001; Schuknecht, 1996).

En materia presupuestal, el contrapeso del gobierno federal mexicano es la Cámara de Diputados, que acorde con el artículo 74 de la Constitución tiene la competencia exclusiva de discutir el presupuesto. Pero la Cámara, durante gran parte del siglo xx, no ha desempeñado funciones de contrapeso o control efectivo en esta materia, y ha tenido un papel activo en la definición del presupuesto de egresos de la federación solamente desde finales de los años noventa, cuando cambió significativamente su composición: a partir de entonces se entró en una etapa de gobierno dividido, en el cual el partido del presidente ya no cuenta con la mayoría absoluta en la Cámara. Anteriormente el Ejecutivo enviaba su iniciativa de presupuesto y contaba con una mayoría para verlo aprobado; en la actualidad esa condición ha cambiado (Ugalde, 2000; Magaloni y Díaz-Cayeros, 1998; Velázquez, 2008).

En general, es posible entonces sostener que el cPp ocurre con mayor probabilidad en un gobierno unificado, que cuenta con mayoría en la Cámara de Diputados, que en uno dividido. Este documento presenta evidencia sobre este tema analizando la interacción entre el Ejecutivo y la Cámara de Diputados en torno a la aprobación del presupuesto, con la intención de determinar si su composición tiene alguna relevancia en la explicación del CPP. Para ello se examina el comportamiento del gasto

\footnotetext{
${ }^{1}$ Si bien Magaloni (2000) menciona que la división de poderes es particularmente relevante para los ciclos fiscales y González (2002) encuentra que la magnitud del ciclo se incrementa con el grado de democracia en el país.
} 
público presentado, aprobado y ejercido, y se determina la presencia (o ausencia) de fluctuaciones acordes con la teoría del cPp. En ese sentido, este trabajo plantea la siguiente hipótesis: un gobierno con mayoría (minoría) en la Cámara de Diputados controla fuertemente (débilmente) el proceso presupuestario, contexto que favorece (desfavorece) la presencia del CPP.

Para probar dicha hipótesis se analizan dos etapas asociadas a las elecciones presidenciales de 1994 y 2006. El primero corresponde al periodo 1992-1995 y el otro al lapso 2004-2007. La selección se hizo con base en el criterio de que el precedente representa la etapa final del sistema de partido dominante, con el titular del Poder Ejecutivo federal y la mayoría de la Cámara de Diputados pertenecientes al mismo partido, el Partido Revolucionario Institucional (PRI). Por su parte, el segundo periodo refleja la consolidación de un gobierno dividido, sin mayoría en la Cámara, como consecuencia de la democratización iniciada en los años ochenta. En cuanto al procedimiento institucional de la elaboración del presupuesto, hay continuidad relativa entre los dos periodos, aunque la reforma constitucional de 2004, como se verá, alteró las reglas del juego ampliando las facultades del legislativo. ${ }^{2}$ De todas formas, consideramos que las dos unidades temporales representan un laboratorio excelente para comprobar la hipótesis formulada.

Nuestros resultados sugieren que un gobierno sin mayoría enfrenta un mayor número de reasignaciones del gasto público por la Cámara de Diputados, lo cual, sin embargo, no elimina la posibilidad de un comportamiento oportunista previsto por la teoría de CPP.

El trabajo se divide en tres apartados. En el primero se presentan las teorías que relacionan factores políticos con el ciclo económico, en relación con la teoría del CPP; además se destaca la cuestión de que un gobierno disponga o no del control de la mayoría parlamentaria. En el segundo se define el procedimiento legislativo en materia presupuestal en México, donde se formaliza la interacción de pesos y contrapesos entre el Poder Ejecutivo y la Cámara de Diputados; asimismo se analiza la recomposición de la Cámara de Diputados que permitió transitar de un sistema de gobierno unificado a otro dividido, teniendo como marco de referencia la composición de las legislaturas que van de la LV a la LX. El tercer apartado está dedicado al estudio del papel de la Cámara de Diputados en la discusión del Proyecto de Presupuesto de Egresos de la Federación (PPEF) y en la aprobación del Presupuesto de Egresos de la Federación (PEF), combinado con el análisis del Gasto Ejercido por la Federación (GEF). El propósito es detectar si existen los siguientes elementos: intenciones

${ }^{2}$ En este sentido, el cambio institucional de 2004 aporta un sesgo favorable a la hipótesis. 
oportunistas del Ejecutivo en el PPEF, aval de la Cámara de Diputados en el PEF, así como acciones oportunistas del Ejecutivo en el GEF; es decir, se determina si existió un CPP en cada una de las elecciones presidenciales analizadas. Finalmente se presentan las conclusiones.

\section{Ciclo político presupuestal: aspectos teóricos}

La teoría de los ciclos políticos tiene sus orígenes a finales de los años treinta y principios de los cuarenta con autores como Schumpeter (1939) y Kalecki (1943), quienes señalaban la aparición de fluctuaciones económicas de naturaleza política. Posteriormente, con la nueva ola de la teoría de la elección pública, se vuelve a abrir la puerta para el estudio de los ciclos económicos asociados a fenómenos políticos (Muñoz, 2006). En particular, gran parte de la literatura moderna sobre ciclos políticoeconómicos tienen su origen en los modelos desarrollados a mediados de los años setenta.

Los trabajos realizados por Nordhaus (1975) y Hibbs (1977) se identifican como los principales puntos de partida de dos tipos de modelos sobre ciclos político-económicos, con perspectivas distintas acerca de las motivaciones de los partidos y de las preferencias de los electores (Borsani, 2003). Según Nordhaus (1975), los gobiernos democráticos, independientemente del signo ideológico del partido que les apoye, pueden utilizar la política económica para generar mejoras de corto plazo en diversas variables clave con fines meramente electorales, por lo que define a estos actores como oportunistas. Es decir, la política económica se puede orientar en función de la proximidad temporal de los comicios: se articulan medidas expansionistas antes de las elecciones y, una vez celebradas éstas, se aplican medidas estabilizadoras, buscando corregir las consecuencias negativas de la política macroeconómica preelectoral. ${ }^{3} \mathrm{Si}$ este manejo electoral de las variables de política induce un patrón cíclico en la producción en torno a la fecha de la elección se genera un CPE.

Sin embargo, la evidencia empírica sobre esta teoría no es definitiva, especialmente para países desarrollados, ${ }^{4}$ Tufte (1978), con base en el análisis de algunos comicios estadounidenses, encontró evidencia de manipulación de diversas variables fiscales con fines electorales, lo que le llevó al planteamiento de la teoría del CPP. Dicha teoría enfatiza el uso de los instrumentos de política fiscal por los gobernantes para incrementar

\footnotetext{
${ }^{3}$ Por ejemplo, inflación y endeudamiento público excesivo.

${ }^{4}$ Algunos ejemplos relevantes son el estudio de Alesina (1989) para EU y de Alesina et al. (1992) para una larga muestra de economías de la Organización para la Cooperación y el Desarrollo Económicos (OCDE).
} 
sus probabilidades de permanecer en el poder, definiendo a estos actores como oportunistas.

Ahora bien, aunque el móvil básico en ambos enfoques sea la manipulación de diferentes instrumentos de política económica para inducir ciertos resultados que permitan ganar votos, difieren por el énfasis en los diversos resultados. La diferencia básica entre el enfoque de Nordhaus (1975) y el de Tufte (1978) consiste en que el primero destaca los resultados de las políticas económicas con fines electorales en términos de crecimiento, desempleo e inflación, en tanto que el segundo se concentra en el uso electoral de los instrumentos de política de impuestos, transferencias y gastos gubernamentales. ${ }^{5}$ Así, el análisis del срP enfatiza la manipulación de los instrumentos de política fiscal como el vehículo a través del cual los gobernantes oportunistas pretenden influir en las preferencias del público, y de esa manera incrementar las probabilidades de victoria electoral.

Esta corriente surge ante la falta de evidencia proporcionada por los modelos tradicionales basados en la política monetaria como instrumento de conducta oportunista (Gámez, 2010). Los argumentos de partida son dos. En primer lugar, el grado de control limitado sobre la política monetaria del que dispone el Ejecutivo, en especial en países donde el banco central es autónomo. En segundo lugar, el manejo de los instrumentos de política fiscal es más propicio para una conducta oportunista por varias razones, entre las que sobresalen que el gobierno tiene un mayor grado de control, especialmente en el gasto público, y que la política fiscal tiene efectos reales, aun si es anticipada, y que puede afectar las condiciones de grupos específicos de votantes incluso si no tiene efectos agregados (Drazen, 2001).

Desde este punto de vista, es relevante considerar las condiciones políticas que aumentan la probabilidad de que el comportamiento oportunista previsto por la teoría se manifieste; es decir, el grado de control que tiene el gobierno en la definición de la agenda pública, en general, y

\footnotetext{
${ }^{5}$ En realidad, la literatura sobre el ciclo político y su influencia en la economía se desarrolló en dos etapas. La primera, que surgió en los setenta, utiliza modelos tradicionales en los cuales los gobiernos pueden influir en los escenarios macroeconómicos de manera sistemática y predecible. Esta primera etapa, a su vez, se expresó en dos vertientes: una de ellas enfatiza la conducta oportunista de los gobiernos, suponiendo que los políticos tiene preferencias propias, mientras que la otra vertiente, conocida como partidista y de la que Hibbs es pionero, plantea que los gobiernos de izquierda tienen ciertas preferencias en materia económica (alto crecimiento y bajo desempleo), mientras los de derecha privilegian una baja tasa de inflación con tasas de desempleo más elevadas). La segunda fase de la literatura se manifestó a mediados de los ochenta, con aplicaciones del enfoque de la teoría de juegos a la política económica. Estos modelos de ciclos económicos incorporan expectativas racionales, y por tanto enfatizan el grado en que un público racional limita los alcances en los que los políticos pueden influir en la economía. En esta corriente también existen vertientes oportunistas y partidistas (Alesina et al., 1997).
} 
el gasto público, en particular, puede verse determinado, entre otras cosas, por factores institucionales, varios de los cuales tienen que ver con características del sistema político: los acuerdos partidarios que culminan en coaliciones de gobierno, el control o no de la mayoría parlamentaria y el grado de disciplina partidaria de los representantes electos, entre otros (Borsani, 2003). En particular, Stein et al. (2006) sostienen que la probabilidad de que el presidente pueda llevar adelante su programa de gobierno depende, entre otras cosas, del tamaño de su contingente y del grado de fragmentación legislativa. Es decir, cuando el presidente cuenta con el apoyo de un partido mayoritario o una coalición disciplinada, la función de la legislatura puede ser limitada, reduciendo su actuación a la aprobación automática de los proyectos del Ejecutivo, con poca capacidad o disposición para analizar con detenimiento y debatir sus contenidos. Por tanto, podría decirse que una legislatura de esta naturaleza no constituye obstáculo alguno para el manejo electoral del gasto público y, en consecuencia, para la generación de un CPP.

Por el contrario, una legislatura en la que el partido del presidente no cuenta con la mayoría absoluta requiere de mayor actividad y costos políticos en la formación de consensos para lograr la aprobación de los proyectos del Ejecutivo, en general, y del presupuesto, en particular. En ese sentido, una legislatura más representativa (plural, diversificada) puede definir mecanismos legales que frenen las tendencias oportunistas del Ejecutivo, ya sea en defensa del interés público o de sus propios intereses partidistas. Ahora bien, aunque un escenario como éste es deseable, también es posible que una legislatura muy fragmentada, en lugar de convertirse en un escenario proactivo de formulación de políticas o de supervisión efectiva del Poder Ejecutivo, tienda a acotar sus funciones, reduciéndose simplemente a la de vetador o foro en el que se negocian gastos con beneficios particulares. Ello puede complicar el proceso legislativo, particularmente la negociación y aprobación del presupuesto, ya que éste tiene plazos decisivos (Stein et al., 2006).

En resumen, considerar las condiciones institucionales en las cuales el gobierno se desempeña es relevante para inferir el grado de libertad que tiene en el manejo de la agenda presupuestaria. En este contexto, es necesario analizar el grado de apoyo que posee el Poder Ejecutivo en la Cámara de Diputados, dado que puede estar facilitando o inhibiendo la manifestación de ciclos presupuestales en la economía. 


\section{La aprobación del presupuesto y la conformación de la Cámara de Diputados de la LV a la LXI Legislatura}

El procedimiento que se sigue en México para la aprobación del presupuesto anual de la federación comprende dos fases esenciales, protagonizadas por dos actores. ${ }^{6} \mathrm{La}$ iniciativa del proyecto de presupuesto es una facultad exclusiva del presidente de la República, quien lo presenta a la Cámara de Diputados. El examen, discusión, modificación y aprobación del proyecto de presupuesto es una facultad exclusiva de la Cámara de Diputados (por ello se define como una función unicameral). ${ }^{7}$ Finalmente, el Ejecutivo federal publica el Decreto de Presupuesto a más tardar 20 días naturales después de la aprobación, y es el responsable último de su ejercicio. El proceso presupuestario involucra, pues, a dos actores que interactúan en el proceso de toma de decisiones fiscales de acuerdo con reglas establecidas, pero con diferentes facultades e incentivos. ${ }^{8}$

La experiencia de México muestra que durante buena parte del siglo $\mathrm{xx}$, la combinación de restricciones institucionales al control legislativo y el régimen de partido hegemónico sustrajeron en realidad el proceso presupuestario de la esfera de acción de la Cámara de Diputados.

Como se observa en el cuadro 1, hasta 1976 la Cámara sólo tenía la misión constitucional de aprobar el presupuesto de egresos, y es apenas en 2004 que se vuelve explícita la posibilidad de aportar modificaciones. Por otra parte, los plazos muy cortos estipulados para el examen presupuestario, agregado a la insuficiencia de recursos e instrumentos técnicos en la Comisión de Presupuesto, impedían una revisión sustancial del documento (Pichardo, 1981).

Hasta los años ochenta, la posición de la Cámara de Diputados con respecto al presupuesto fue acomodaticia y dependió de la composición del Congreso, en el que el Ejecutivo federal contaba con un predominio absoluto, de manera que la Cámara se limitaba a la aprobación del pPeF presentado por el primero. Esta situación cambió de manera significativa, según Ugalde (2000), hacia 1998, año a partir del cual se verificaron

\footnotetext{
${ }^{6}$ Las facultades exclusivas que tiene cada actor participante en el proceso presupuestario están reguladas constitucionalmente en los artículos 71, 72 y 74, fr. IV, y por el artículo 42 de la Ley Federal de Presupuesto y Responsabilidad Hacendaria (su ley reglamentaria).

${ }^{7}$ Además del presupuesto de egresos, en el sistema mexicano la Cámara de Diputados tiene a su cargo otras dos funciones relativas a las finanzas públicas: la aprobación de la Ley de Ingresos y la revisión de la cuenta pública.

${ }^{8}$ En la medida que el federalismo se ha hecho más efectivo, el proceso presupuestario se ha vuelto más complejo, al pasar de un juego de dos actores homogéneos a otro en el que uno de ellos se ha fragmentado, ofreciendo la posibilidad de intervención, por ejemplo, de los gobernadores a través de sus diputaciones federales.
} 


\section{Cuadro 1}

Restricciones institucionales en el proceso presupuestario, 1917-2004

\begin{tabular}{lll}
\hline & Facultades de la Cámara de Diputados & $\begin{array}{c}\text { Plazo para la discusión en } \\
\text { la Camara de Diputados }\end{array}$ \\
\hline $1917-1976$ & Aprobar el presupuesto & 15 días \\
\multirow{2}{*}{$1977-2003$} & $\begin{array}{l}\text { Examinar, discutir y aprobar } \\
\text { el presupuesto }\end{array}$ & 30 días \\
$2004-$ & $\begin{array}{l}\text { Examinar, discutir, modificar } \\
\text { y aprobar el presupuesto }\end{array}$ & 67 días \\
\hline
\end{tabular}

Fuente: Elaboración propia con base en Derechos del pueblo mexicano (2006).

cambios importantes a los proyectos originales del Ejecutivo, aun cuando las enmiendas se iniciaron desde los años ochenta. ${ }^{9}$

Así, durante décadas la división efectiva del poder no fue una característica del sistema político en México. La mayoría del partido del presidente, el Partido Revolucionario Institucional (PRI), estaba garantizada en el Congreso, y la oposición, aun unificada, siempre estuvo lejos de alcanzar la mayoría simple necesaria para frenar las iniciativas del Ejecutivo y su partido. ${ }^{10}$ Sin embargo, la situación cambió paulatinamente debido a una serie de reformas y a la aparición de nuevos actores políticos, de manera que el PRI pasó de una posición hegemónica a comienzos de los años setenta a una predominante en el transcurso de los ochenta (Casar, 2001).

Sin lugar a dudas, las reformas llevadas a cabo a partir de 1977 provocaron profundos cambios en la estructura de las cámaras, pues dieron pauta a la creación de una mayor competencia electoral, permitiendo la entrada de nuevos jugadores al escenario político. Específicamente, se flexibilizaron los requisitos para ingresar al sistema formal de partidos y se modificó la fórmula de integración de la Cámara de Diputados, lo que incrementó el número de diputados de mayoría y los elegidos por criterios de proporcionalidad (CD, 2005). Estas modificaciones marcaron un punto de inflexión importante pues, sin dejar atrás el sistema de partido hegemónico, permitieron el avance del Partido Acción Nacional (PAN) y la incorporación de nuevos partidos que detonaron una competencia efectiva, principalmente a partir de la elección presidencial de 1988.

\footnotetext{
9 Según Magaloni y Díaz-Cayeros (1998), no fue sino hasta 1982 cuando se comenzaron a registrar enmiendas a los montos totales de las iniciativas presidenciales, que generalmente involucraban aumentos respecto a los montos originalmente solicitados.

${ }^{10}$ De 1964 a 1976, el PRI concentró, en promedio, 83\% de los asientos en la Cámara de Diputados y $100 \%$ en la de Senadores. De 1979 a 1985 el promedio de diputados para el pRI fue de $75 \%$ (Casar, 2001).
} 
Desde entonces, el sistema partidista de México se ha integrado esencialmente por tres partidos que son los que encabezan las preferencias electorales: PRI, PAN y Partido de la Revolución Democrática (PRD). Adicionalmente, durante los últimos años otros partidos han gozado de presencia en el Congreso de la Unión y en los congresos locales, e incluso han participado en las elecciones presidenciales en alianza con alguno de los tres grandes partidos. ${ }^{11}$

Así, durante los años ochenta y noventa el sistema político mexicano, que en un largo periodo se mantuvo en una situación de bajas o nulas competencia real y competitividad, se fue transformando. ${ }^{12}$ La competitividad se implantó a partir de los años ochenta sobre la base de un sistema de partidos que había empezado a modificar sus reglas de funcionamiento desde finales de los años setenta.

La nueva organización en las cámaras se reflejó también en la ampliación de los grupos parlamentarios, ${ }^{13}$ a través de los cuales los partidos políticos han podido influir indirectamente en el proceso de formulación de políticas, por ejemplo en las relaciones entre los poderes Ejecutivo y Legislativo, en las posibilidades de coordinación en el Congreso y en los incentivos de los funcionarios electos para atender conjuntos más estrechos o más amplios de intereses de la sociedad (Stein et al., 2006).

Por su parte, aunque los partidos minoritarios tienen un menor peso electoral y un reducido número de legisladores, se debe señalar que cada vez más han adquirido importancia porque son los que permiten a los tres partidos más grandes formar mayorías legislativas, cuando por sí solos no alcanzan mayoría legislativa. En este sentido el voto de estos pequeños partidos inclina la balanza a un lado o al otro.

El cambio político culminó con la pérdida de la mayoría absoluta del PRI en la Cámara de Diputados en $1997 .{ }^{14}$ A partir de entonces cualquier iniciativa requeriría la construcción de consensos y alianzas en la Cámara de Diputados. El efecto de esta nueva composición se hizo sentir de in-

${ }^{11}$ Estos son: Partido Alternativa Socialdemócrata, Partido del Trabajo (РT), Convergencia, Partido Verde Ecologista de México (PVEM), Partido Socialdemócrata (PSD) y Partido Nueva Alianza (Panal) (Valdés, 1988). Todos ellos han conformado el Congreso de la Unión y han tenido una participación política activa.

${ }^{12} \mathrm{La}$ competencia se refiere a reglas formales e informales del juego político, las cuales permiten que los partidos concurran en términos reales de igualdad y equidad, mientras que la competitividad remite al estado del juego en un momento determinado (bajo este término no habrá competitividad si la gran mayoría de los ciudadanos sufragan por una de las opciones (Sartori, 1980).

${ }^{13}$ Son las formas de organización que pueden adoptar los diputados pertenecientes a un mismo partido político. Al respecto, el artículo 70 constitucional establece que estarán conformadas por no menos de cinco diputados, quienes podrán constituir un solo grupo parlamentario y deberán contribuir al mejor desarrollo del proceso legislativo.

${ }^{14}$ Ese año, las elecciones intermedias dieron como resultado una Cámara de Senadores en la que el PRI conservó la mayoría absoluta $(50 \%+1)$, pero una Cámara de Diputados en la que ningún partido obtuvo la mayoría necesaria para aprobar las iniciativas de ley. 
mediato en el área presupuestal. El Ejecutivo y su partido no estarían en posibilidad de asegurar la aprobación de la Ley de Ingresos y el Presupuesto de Egresos. Según Casar (2001), por primera vez se enfrentó la necesidad de sumar intereses al interior del Poder Legislativo con el fin de ver aprobado el presupuesto.

En el cuadro 2 se muestra la composición de las bancadas que integraron la Cámara de Diputados durante los periodos 1991-1997 y 20032009. ${ }^{15}$ Se observa que hasta la LVI Legislatura (1994-1997) el grupo parlamentario del PRI tuvo la representación para conformar el quórum necesario para la apertura de la sesión y para aprobar el presupuesto. Sin embargo, a partir de la LVII Legislatura los gobiernos de mayoría se acabaron, se inició así la etapa de los divididos. Desde entonces la composición de la Cámara de Diputados ha enriquecido el proceso de aprobación del presupuesto, pues ningún grupo parlamentario ha logrado el control mayoritario en la Cámara, conformándose bancadas de minorías con menos de 251 diputados electos. El PRI, el PAN y el PRD, en las últimas cinco legislaturas, se han alternado la primera, segunda y tercera minoría.

Así, desde la LVII Legislatura (1997-2000) el proceso de aprobación del presupuesto se ha realizado a través de la conformación de alianzas entres dos o más fuerzas políticas, conllevando a una negociación cuya principal característica ha sido que las bancadas parlamentarias que construyen las mayorías impulsan de forma más amplia sus intereses y programas presupuestarios.

\section{Aprobación del presupuesto y ciclo político presupuestal}

El análisis del ciclo político presupuestal se realizó para dos escenarios diferenciados, que incorporan comicios presidenciales: los gobiernos de mayoría, emanados del partido hegemónico, cuando la conformación del quórum y la aprobación del presupuesto corrían a cargo de la bancada mayoritaria (periodo 1992-1995); y los gobiernos divididos, en los que dos o más bancadas conformaban alianzas para reunir el quórum y aprobar el presupuesto (periodo 2004-2007). ${ }^{16}$

\subsection{Ciclo político presupuestal y gobiernos con mayoría: 1992-1995}

Durante los gobiernos con mayoría que emanaban del PRI, la relación entre el Poder Ejecutivo federal y el Congreso de la Unión fue de una

\footnotetext{
${ }^{15}$ Sólo se presentan las legislaturas del periodo de estudio.

${ }^{16}$ Es condición necesaria para aprobar el PEF que deban estar reunidos en el salón de sesiones al menos 251 legisladores, y además contar con una mayoría absoluta, entendiéndose ésta como la votación a favor del dictamen del 50\% + 1 de los diputados presentes en el momento de la votación.
} 


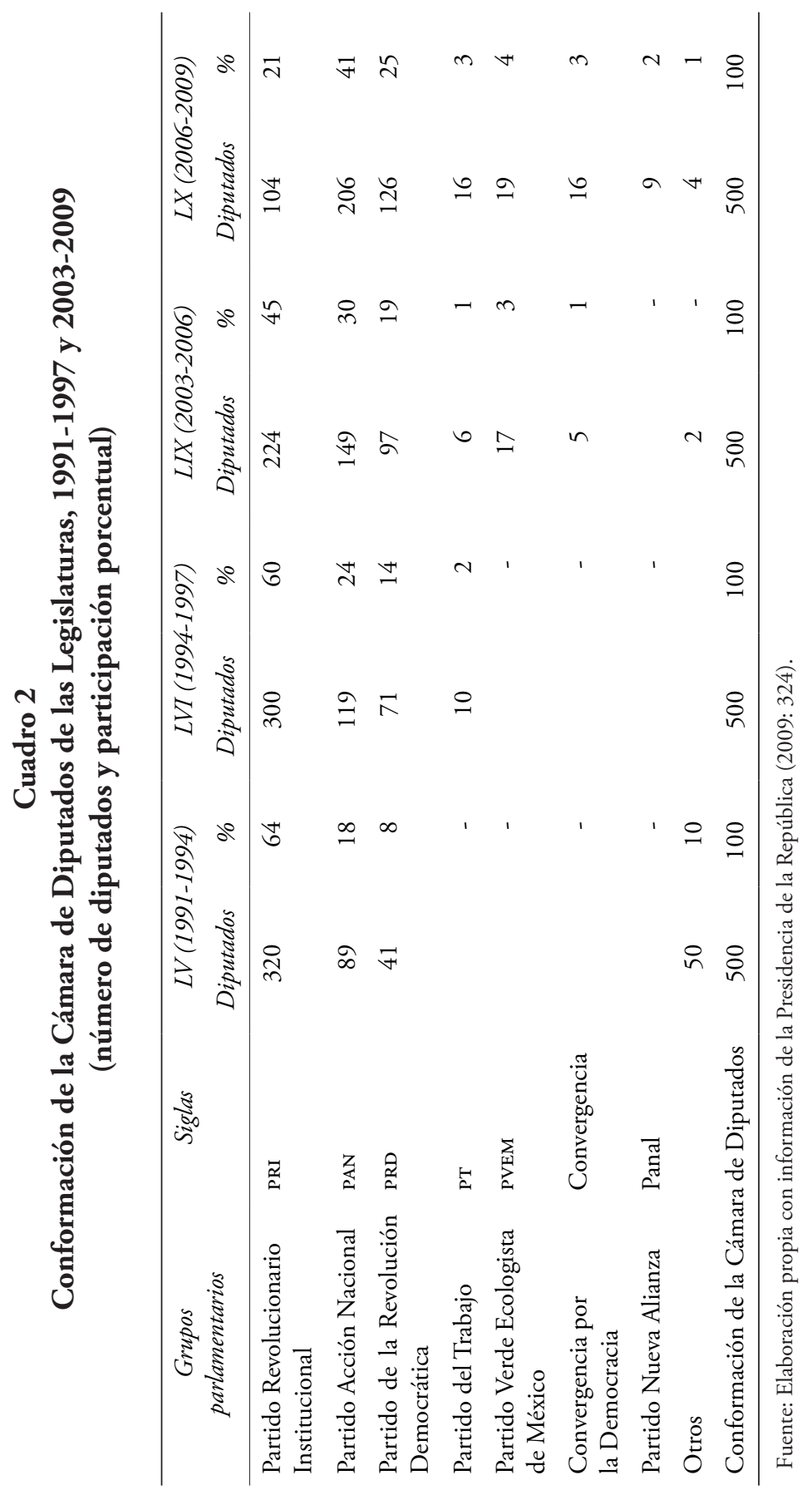




\section{Gráfica I}

Comparativo del proyecto y el gasto aprobado para los ejercicios fiscales 1992-1995

(millones de pesos constantes, 1993)

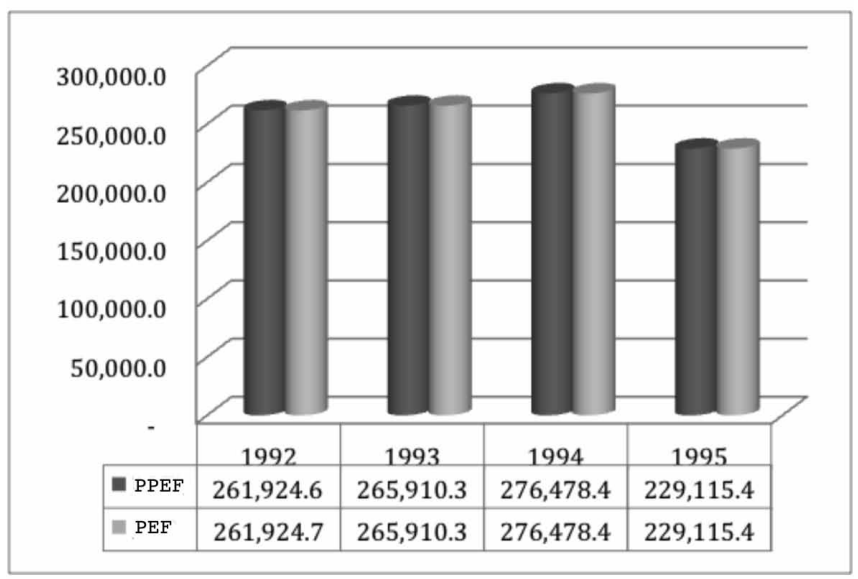

Fuente: Elaboración propia con datos de Presidencia de la República (1991-1994a) y del Diario Oficial de la Federación (1991-1994).

subordinación del segundo hacia el primero debido a los poderes metaconstitucionales del presidente de la República, que además de ser jefe de Estado y jefe de gobierno, también era el jefe del partido (Weldon, 1997). ${ }^{17}$ Por ello, el Congreso de la Unión renunció de facto a su función de contrapeso del Ejecutivo federal, allanándole al presidente de la República la tarea de gobernar para que éste garantizara la continuidad de la carrera política de los miembros del Poder Legislativo (Ugalde, 2000).

El procedimiento legislativo en materia presupuestaria-como el resto de los instrumentos de políticas públicas sometidas por el Ejecutivo federal al Congreso o a una de sus cámaras- se redujo a un examen y discusión casi nulos por parte de los diputados, en el que ampliaciones en un ramo se compensaban con reducciones en otros ramos, y viceversa. Como consecuencia, el presupuesto agregado aprobado coincidía en su totalidad con el proyecto enviado por el presidente de la República (Ugalde, 2000). En la gráfica i se observa que la aprobación de los miembros de la Cámara de Diputados ante la iniciativa presupuestal del Ejecutivo, durante el periodo 1992-1995, era absoluta: la diferencia entre el PPEF y

${ }^{17}$ En esta dualidad gobierno-PRI, el presidente se erigía también como el gran elector, de cuya aprobación dependían todos los cargos, tanto los de elección popular como los que no lo eran. 
el PEF fue nula, es decir, el monto total de la iniciativa enviada por el Ejecutivo no tuvo modificaciones por parte de la Cámara de Diputados. ${ }^{18}$

En un análisis de introspección de los ramos que conformaban el presupuesto durante los ejercicios fiscales 1992-1995, se observa una estrategia de reasignación de suma cero, de manera que los aumentos autorizados por la Cámara de Diputados a favor de uno o más ramos, se compensaban con disminuciones o recortes por la misma cantidad para otro u otros ramos. Por ejemplo, en el ejercicio 1992 la Cámara de Diputados autorizó una reducción de 57 millones de pesos (a precios de 1993) a cargo del ramo 23 (erogaciones no sectorizables), y la compensó con una ampliación de 57 millones de pesos a favor del ramo 01 (Poder Legislativo); en los años posteriores se observa un comportamiento similar, a excepción del ejercicio fiscal de 1994, en el que no se modificó ningún ramo del presupuesto (cuadro 3).

Además, es importante señalar que de los rubros que tuvieron disminuciones, el ramo 23 está entre los primeros lugares en cuanto a la participación porcentual en el PPEF (en 1992 y 1993 presentó una participación de 8.2 y $10.4 \%$, respectivamente). ${ }^{19}$

Del análisis del gasto público propuesto y aprobado durante los gobiernos con mayoría parlamentaria, se observa que la Cámara de Diputados pareciera haber renunciado a su facultad de enmendar significativamente el proyecto de presupuesto. Este arreglo institucional implicó la escasa incidencia del Congreso en el rumbo de la política económica del país y, para fines de este trabajo, proporcionó un escenario propicio para la generación de un CPP al permitir que el Ejecutivo federal tuviera un mayor control del presupuesto para ejercerlo de acuerdo con sus intereses (que pudieran ser o no oportunistas).

En la gráfica II se observa que tanto el PPEF como el presupuesto aprobado y ejercido siguen el comportamiento sugerido por la teoría del CPP, es decir, una expansión antes de elecciones y una contracción después. En 1995, el Ppef enviado fue de 229,115 millones de pesos (a precios de 1993), lo que representaba una contracción de $17.13 \%$ en comparación con el de 1994. Aunque en principio pudiera pensarse que fue la crisis económica de ese año la que determinó esa contracción, es relevante resaltar que la iniciativa se envió 11 días antes de que se suscitara la citada crisis. ${ }^{20}$ De hecho, el Ejecutivo presentó al Congreso los llamados "Cri-

${ }^{18}$ Por ejemplo, para 1992 la iniciativa contempló 261,924.6 millones de pesos, y fue aprobada por la misma cantidad; este comportamiento fue constante durante el periodo de estudio.

${ }^{19}$ En este periodo de estudio, el presupuesto asignado a las empresas paraestatales tiene la mayor participación porcentual en el PPEF, seguida del ramo 28 (Participaciones a Entidades Federativas).

${ }^{20}$ El 20 de diciembre de 1994, ante la falta de divisas, el gobierno se vio obligado a depreciar el peso (ampliando la banda de flotación), y al consultarlo con representantes del sector privado, hubo una fuga de capitales inmediata que disminuyó las reservas en unos 5,000 millones de dólares. El 


\section{Cuadro 3}

\section{Reasignaciones hechas al proyecto de presupuesto para los ejercicios fiscales 1992-1995 (millones de pesos constantes a precios de 1993)}

\begin{tabular}{|c|c|c|c|c|}
\hline Ramos & 1992 & 1993 & 1994 & 1995 \\
\hline 01 Poder Legislativo & 57.02 & 0.00 & 0.00 & 0.00 \\
\hline $\begin{array}{l}08 \text { Agricultura y Recursos } \\
\text { Hidráulicos }\end{array}$ & 0.00 & 350.00 & 0.00 & 70.97 \\
\hline $\begin{array}{l}10 \text { Comercio y Fomento } \\
\text { Industrial }\end{array}$ & 0.00 & 0.00 & 0.00 & 74.21 \\
\hline $\begin{array}{l}16 \text { Medio Ambiente, } \\
\text { Recursos Naturales y Pesca }\end{array}$ & 0.00 & 0.00 & 0.00 & -145.18 \\
\hline $\begin{array}{l}23 \text { Erogaciones no } \\
\text { Sectorizables* }\end{array}$ & -57.02 & -350.00 & 0.00 & 0.00 \\
\hline PPE-PEF total & 0.00 & 0.00 & 0.00 & 0.00 \\
\hline
\end{tabular}

* A partir de 1995 se denomina Provisiones Salariales y Económicas.

Fuente: Elaboración propia con información de los Proyectos y Presupuestos de Egresos de la Federación para los ejercicios fiscales 1992-1995.

terios generales de política económica" (que acompañaban a la ley de ingresos y presupuesto de egresos de la Federación) en los que se incluyó un diagnóstico preciso de lo acontecido en 1994: un crecimiento del PIB de $3.1 \%$ (no obstante los trágicos acontecimientos sucedidos en el ámbito nacional), una inflación de $4 \% \mathrm{y}$, en materia de finanzas públicas, un equilibrio en el balance económico. En ese sentido, el presidente Zedillo destacó que este equilibrio permitiría que, al término de ese año, el saldo de la deuda pública neta consolidada con el Banco de México (1995) se mantuviera en un porcentaje del PIB similar al del ańo anterior, que se ubicó en $2.2 \%$. Respecto a las proyecciones económicas para 1995, destacaba un crecimiento del pIв de 4\%, una inflación de $4 \%$, una cotización del peso casi al mismo nivel de 1994 y un déficit en cuenta corriente que se pronosticaba en 7.8\% del pib (Presidencia de la República, 1994b). Es decir, en esencia la política económica se mantendría sin cambios, lo que para muchos analistas parecía poco factible. Al respecto Cárdenas (1996) comenta que las proyecciones para 1995 parecían haber sido hechas por el equipo saliente y no se sabía hasta dónde había participado el gobierno entrante. Así, podría decirse que el nuevo gobierno, al no anunciar cambios importantes de política económica, aceptó implícitamente las pro-

tipo de cambio llegó a 5.10 pesos por dólar al terminar el año, 48\% más elevado que su nivel un mes antes, y las reservas internacionales del Banco de México quedaron en 6.2 mil millones de dólares (Cárdenas, 1996). 


\section{Gráfica II \\ Proyecto de presupuesto aprobado y ejercido, 1993-1995 (tasa de crecimiento calculada en millones de pesos constantes a precios de 1993)}

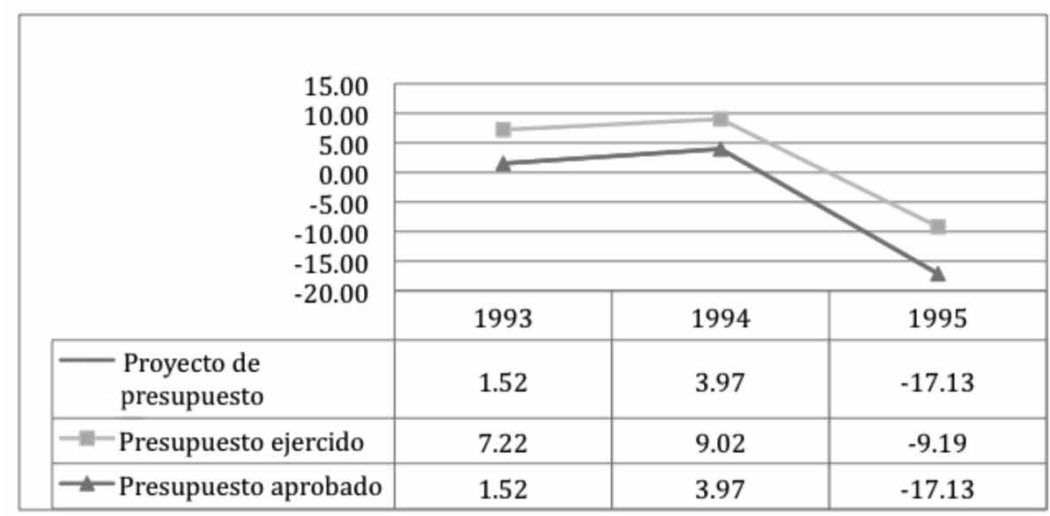

Fuente: Elaboración propia con datos del Diario Oficial de la Federación (1991-1994) y CD (2001).

yecciones presentadas en los "Criterios generales"; postura que no proporcionaba el sustento económico para instrumentar una contracción del gasto público.

Por su parte, la Cámara de Diputados tampoco anunció cambios, pues el pef aprobado el 28 de diciembre de 1994 se publicó con la misma suma neta total que la iniciativa del Ejecutivo, aun cuando la economía mexicana ya había entrado en crisis, lo que sugiere una gestación previa del CPP, respaldado por la Cámara de Diputados.

Hasta ahora se ha señalado la intención oportunista del Ejecutivo acompañada de la aprobación de la Cámara, de lo cual vale la pena resaltar cómo a partir de los sistemas institucionales de pesos y contrapesos débiles, la pasividad de la Cámara de Diputados en sus funciones legislativas en materia presupuestaria creó o facilitó el escenario para la presencia del CPr. En este contexto, lo que sigue corresponde a examinar el gasto público ejercido para determinar si efectivamente se materializó el CPP.

El gasto ejercido por el gobierno se reporta en la Cuenta de la Hacienda Pública Federal (CHPF). Éste es un indicador útil para evidenciar la existencia de gobiernos oportunistas ante la posibilidad de que el gasto ejercido difiera del aprobado por la Cámara.

El comportamiento del gasto ejercido durante el periodo 1992-1995 evidencia un comportamiento oportunista, ya que esta variable aumentó de forma sucesiva hasta el año de la elección, para contraerse inmediatamente después de la celebración del proceso electoral, y de forma independiente, como se ha visto, de los pronósticos macroeconómicos. En la 
gráfica II se observa cómo en 1994, año de elección presidencial, el Ejecutivo federal ejerció un gasto público superior en $9 \%$ al ejercido en 1993; también se muestra una contracción de $9 \%$, en 1995, en relación con el gasto de 1994. Es importante subrayar que esta contracción estaba considerada desde el PPEF, por lo que no se debe atribuir exclusivamente a la recesión que experimentó la economía nacional en la primera mitad de 1995. ${ }^{21}$ Más aún, resulta interesante observar que el gasto ejercido disminuyó menos que la iniciativa presentada por el Ejecutivo, lo que podría ser resultado de la rápida recuperación de la economía al presentar en el tercer trimestre de 1995 una recuperación de la producción. ${ }^{22}$

Adicionalmente, al estudiar el presupuesto aprobado y el gasto ejercido se observa una notoria discrepancia. ${ }^{23}$ En el cuadro 4 se presenta la variación porcentual del gasto ejercido respecto al gasto aprobado en los cinco principales ramos que presentaron mayor diferencia.

Aunque no existe un patrón bien definido, se puede decir que entre los ramos presupuestales que más han presentado variaciones se encuentran Energía, Minas e Industria Paraestatal, Desarrollo Urbano y Ecología, y Reforma Agraria, éste último señalado como una fuente importante de clientelismo electoral (Magaloni y Díaz-Cayeros, 1998). Además, se encuentran ramos en los que casi siempre se ha ejercido un gasto superior al autorizado, como en el Poder Judicial y en Hacienda.

En resumen, se puede afirmar que durante los gobiernos con mayoría el procedimiento se redujo a la presentación del proyecto de presupuesto por parte del Ejecutivo federal y la aprobación, con reasignaciones de suma cero, por parte de la Cámara de Diputados, lo que implicaba que, en términos agregados, el gasto propuesto coincidía con el aprobado. Así, podría decirse que la Cámara de Diputados no representó ningún obstáculo para que el gobierno federal manipulara el presupuesto con fines electorales. Por el contrario, la política de gasto público aprobada permitió la presencia de CPP en torno a la elección presidencial de 1994.

\subsection{Ciclo politico presupuestario y gobiernos divididos: 2004-2007}

El contexto analizado anteriormente induce a indagar si la presencia de los ciclos presupuestales se limita en caso de gobierno dividido, donde el

${ }^{21}$ Durante el primer semestre de 1995 , el PIB disminuyó $5.8 \%$ con respecto al mismo periodo del año anterior. El gasto del consumidor y la inversión pública y privada bajaron $14.7 \%$ en relación con el nivel establecido en el mismo periodo en 1994 (Ortega, 2006).

22 Después de que el pIB presentó tasas de crecimiento negativas en los dos primeros trimestres de 1995 , de -4.7 y $-5.9 \%$, respectivamente, durante el tercer trimestre se tuvo un crecimiento de 1.3\%. Para mayor detalle véase Lustig (2002), quien examina, entre otras cosas, los factores que están detrás de la rápida recuperación económica posterior a la crisis.

${ }^{23}$ Para mayor detalle sobre las deficiencias de fiscalización en el gasto público, véase Ugalde (1997). 


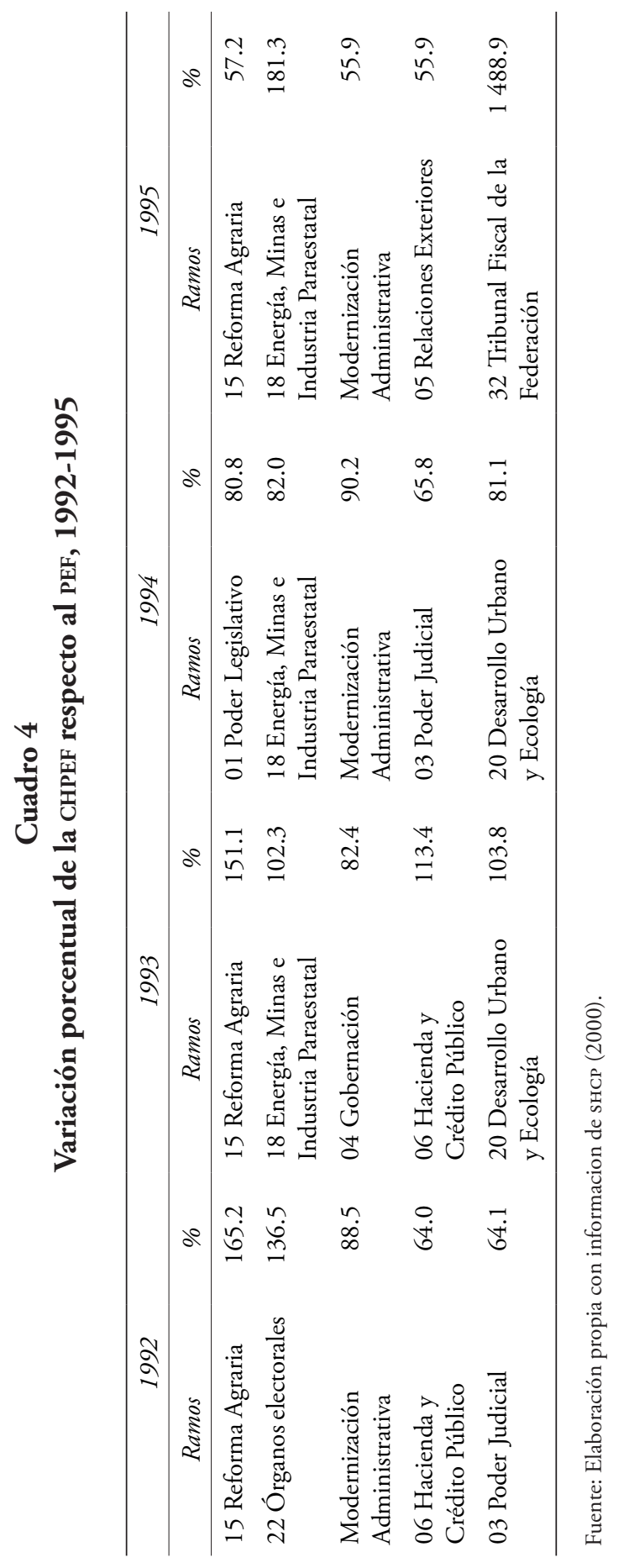


Ejecutivo carece de mayoría en la Cámara de Diputados. En este apartado se proporcionara evidencia al respecto para el periodo 2004-2007.

La garantía de contar con la mayoría en la Legislatura se vio alterada, como se mencionó, a consecuencia de la creciente presencia de los partidos de oposición y de las reformas político-electorales que desde 1977 se han sucedido. ${ }^{24} \mathrm{La}$ transformación ha sido tan radical, que en la LVII Legislatura (1997-2000) México tuvo por primera vez en la historia contemporánea un gobierno dividido, y este escenario ha prevalecido desde entonces. Los cambios realizados en el sistema de pesos y contrapesos generaron, a su vez, variaciones en el sistema de incentivos y resaltaron la importancia de los acuerdos institucionales dentro del Congreso en general, y en la Cámara de Diputados, en particular. Al respecto, algunos trabajos señalan que la composición de la Cámara es un factor determinante para llegar a acuerdos y que ésta, en su trayectoria, ha acomodado prácticas que van desde la disciplina partidista estricta hasta la capacidad para lograr coaliciones (Casar, 2001; Ugalde, 2000). ${ }^{25}$ Sin embargo, cuando el PAN obtuvo la presidencia y careció de una mayoría, la Cámara se convirtió en un participante mucho más activo en la formulación de políticas y el índice de éxito de las iniciativas del Poder Ejecutivo se redujo considerablemente.

Así, la evidencia muestra que los gobiernos sin mayoría modificaron la relación entre el Ejecutivo federal y los miembros del Congreso, que pasaron de ser una cooperación incondicional para tornarse incluso conflictiva, porque al existir un régimen de alternancia en el poder (desaparición del partido hegemónico), el presidente dejó de ser el gran elector, su bancada era minoritaria y enfrentó costos políticos mayores en el Congreso para aprobar los proyectos de ley que el Ejecutivo federal sometía al Congreso (Sour et al., 2004; Casar, 2001; Ugalde, 2000). ${ }^{26}$

A continuación se presentan las modificaciones realizadas al PPEF de 2004 a 2007. Específicamente a partir de 1997, con la instauración del primer gobierno dividido, la labor de la Cámara de Diputados en materia presupuestaria ha sido más activa. Al ejercer su facultad exclusiva de modificar el presupuesto, ha hecho reasignaciones a diversos ramos que integran el presupuesto, con el resultado de salir del juego de suma cero.

${ }^{24}$ Para mayor detalle respecto al contenido de las reformas, véase Cámara de Diputados $\mathrm{H}$. Congreso de la Unión (2005) y Valdés (1988).

${ }^{25}$ Las elecciones de 2000 son un claro ejemplo de ello, pues debido a su composición se destaca en este proceso la necesidad de negociar y concertar alianzas (Casar, 2001).

${ }^{26}$ Por ejemplo, el presupuesto de egresos para 2005 dio lugar a una controversia constitucional entre la Cámara de Diputados y la presidencia, de la que se ocupó la Suprema Corte de Justicia. La Cámara había modificado algunos programas, reduciendo el financiamiento de algunos rubros a fin de aumentar el financiamiento para otros programas vigentes y nuevos renglones; ante lo cual, el Ejecutivo ejerció el derecho de veto, que los diputados rechazaron (OCDE, 2009). 


\section{Gráfica III \\ Comparativo del proyecto y el gasto aprobado para los ejercicios fiscales 2004-2007 \\ (millones de pesos constantes, 1993)}

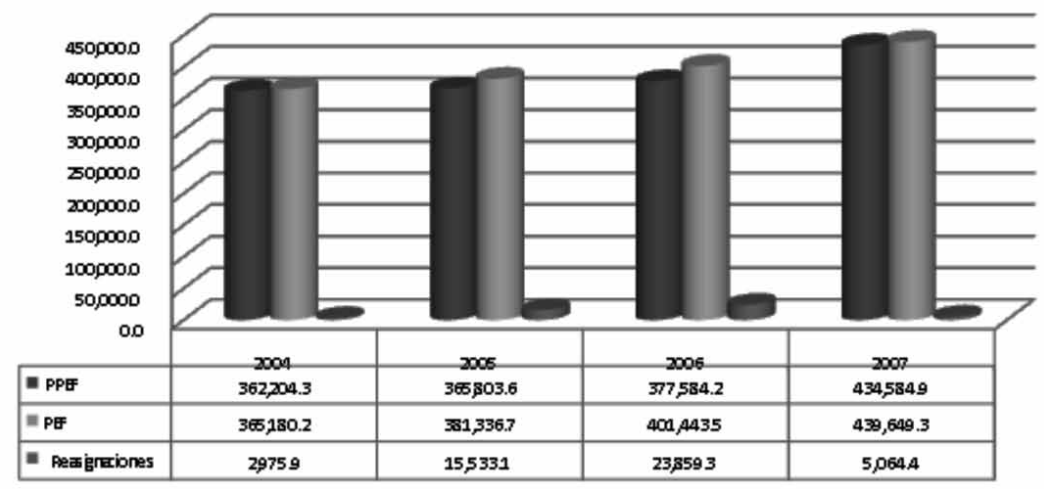

Fuente: Elaboración propia con datos de Presidencia de la República (2009) y Diario Oficial de la Federación (2003-2006).

En el año 2004, el Ejecutivo federal propuso un gasto neto total de 362,204 mdp constantes, y la Cámara de Diputados autorizó 365,180 mdp; es decir, el presupuesto tuvo una leve ampliación; este tipo de enmiendas al presupuesto se fue incrementando durante los años siguientes; en pesos constantes de 1993, las reasignaciones hechas por la Cámara de Diputados fueron equivalentes a 2,975 mdp en el año 2004; 15,532 en el año 2005; 23,859 en 2006 y a 5,064 mdp en el año 2007 (gráfica III). ${ }^{27}$

Las reasignaciones autorizadas por la Cámara de Diputados al presupuesto promediaron, en este periodo, $3.1 \%$ respecto al gasto aprobado: en el año 2004 fueron de $0.8 \%$; en 2005 representaron 4\%; en 2006 ascendieron a $5.9 \%$ y a $1.1 \%$ en 2007 , como se observa en la gráfica IV. En este caso, las reasignaciones de 2005 y 2006 reflejan ańos de elecciones presidenciales. $^{28}$

Como consecuencia de las enmiendas, los ramos que tuvieron los mayores incrementos fueron: Provisiones Salariales y Económicas, Comunicaciones y Transportes, Programa de Apoyo para el Fortalecimiento

${ }^{27}$ Cabe señalar que en diciembre de 2004 el presidente de la República presentó ante la Suprema Corte de Justicia de la Nación una controversia constitucional contra la Cámara de Diputados, que tiene su origen en la decisión de la Cámara de no atender a las observaciones del Ejecutivo federal al presupuesto de egresos de 2005. La Suprema Corte resolvió que el titular del Ejecutivo federal sí tiene facultad para vetar el presupuesto (scJN, 2005: 154).

${ }^{28}$ Esta cifra es bastante menor en muchos países con regímenes parlamentarios, donde en el caso extremo un gobierno puede caer si se modifica el presupuesto. Sin embargo, en países comparables con regímenes presidenciales, como Brasil o Argentina, se observan modificaciones de magnitud similar (OCDE, 2009: 83). 


\section{Gráfica IV}

\section{Reasignaciones hechas al proyecto de presupuesto para los ejercicios fiscales 2004-2007 (participación en el presupuesto total aprobado)}

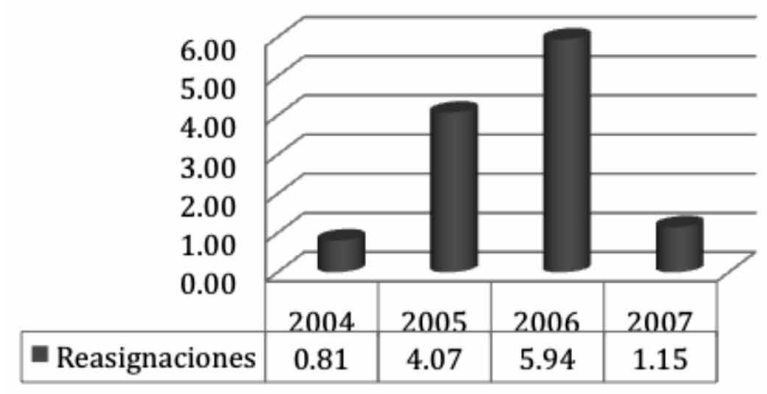

Fuente: Elaboración propia con datos de Presidencia de la República (2009) y Diario Oficial de la Federación (2003-2006).

de las Entidades Federativas, Reforma Agraria, Tribunales Agrarios y Medio Ambiente y Recursos Naturales (cuadro 5). Cabe destacar que algunos de estos ramos, como el 39, 16 y 23, contienen programas presupuestarios con gasto identificado para entidades federativas. Ello permite suponer que, dado que el principal partido opositor (PRI) tenía la mayoría relativa de diputados, entonces la capacidad de los legisladores panistas para hacer llegar recursos al Ejecutivo federal era baja; además pudo derivar en una motivación legislativa compartida hacia la asignación de recursos estatales. ${ }^{29}$

Por lo visto, los resultados encontrados sugieren que la composición de la Cámara de Diputados y los incentivos de los legisladores han tenido influencia en el volumen de gastos autorizados, ya que las enmiendas realizadas a los proyectos presentados por el Ejecutivo se han ampliado con un Congreso más plural. Al respecto, Gámez e Ibarra (2009) explican que una vez que se agudizó la competencia política (y el PRI comenzó a perder la gubernatura de varios estados), es fácil suponer un cambio de incentivos por parte de los diputados, si además se considera que en el juego oportunista los beneficios políticos de las conductas oportunistas

${ }^{29}$ A partir de los años 2000 y 2001 se transfirieron mayores recursos a los gobiernos estatales a través del Programa de Apoyo para el Fortalecimiento de las Entidades Federativas (PAFEF) creando el Ramo 23, el cual provee recursos para atender erogaciones contingentes, como el retiro voluntario, los efectos de desastres naturales y las aportaciones del gobierno federal al ahorro de los trabajadores del sector público, entre otros (CD, 2009). Aun cuando estos recursos no están descentralizados porque no están suscritos en la Ley de Coordinación Fiscal, tienen como finalidad apoyar a las haciendas estatales (saneamiento financiero), mejorar la calidad de la educación, apoyar el empleo a escala regional, los sistemas de pensiones locales y a la inversión de la infraestructura de las entidades federativas. 


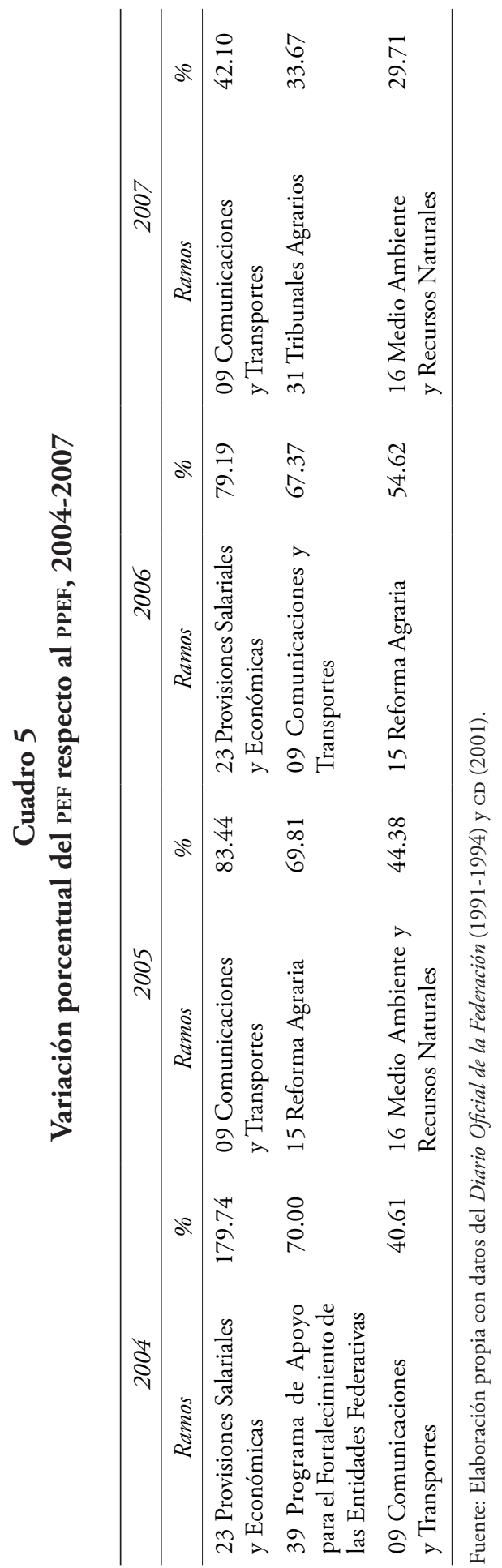


de los gobiernos podrían verse repartidos entre los niveles estatal y federal. De hecho, en México una fracción sustancial de los gastos depende de transferencias federales con destinos predeterminados (como el ramo 33).

Respecto a las reasignaciones, hay que destacar dos aspectos: la participación de la Cámara de Diputados en la aprobación del pef fue indudablemente más activa que en periodos donde el gobierno contaba con mayoría (Anexo I). Sin embargo, contrario a lo que se esperaba, la composición de la Cámara de Diputados que aprobó el pef de 2004 a 2006 (integrada por $45 \%$ del partido opositor) no fue un factor que limitara cuantitativamente la iniciativa del Ejecutivo; por el contrario, las enmiendas significaron un mayor tamaño del gasto federal, siendo el año electoral el que presenta un incremento máximo, al asignarle al PPEF 23,859.3 millones de pesos más (gráfica III).

Así, durante el periodo de estudio se observan, en primer lugar, iniciativas con montos crecientes acompañados de presupuestos aprobados que contienen cifras mayores a las propuestas; y en segundo, una iniciativa de presupuesto para 2007 que solicitaba 57,000 millones de pesos (a precios de 1993) más que la de 2006; la tasa de crecimiento del PPEF para 2007 es de 15.09, casi 5 veces más que la de 2006; sin embargo, el PEF aprobado ese año, si bien presentó un aumento, éste fue menor comparado con las ampliaciones de los años anteriores (gráfica v). Es necesario resaltar que el presupuesto para 2007 se aprobó en condiciones de mayoría relativa. ${ }^{30}$

\section{Gráfica V}

Proyecto de presupuesto aprobado y ejercido, 2005-2007 (tasa de crecimiento calculada en millones de pesos constantes a precios de 1993)

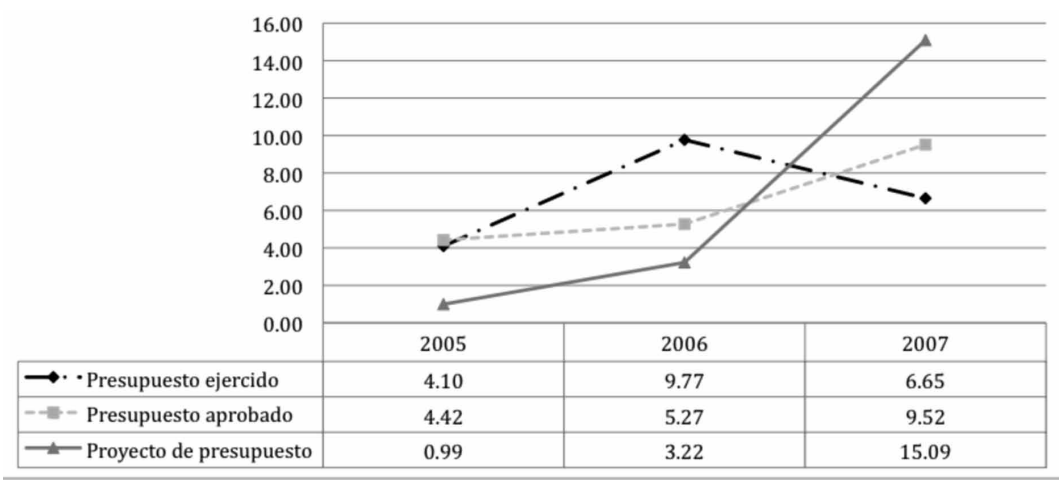

Fuente: Elaboración propia con datos del Diario Oficial de la Federación (2003-2006) y sнсP (2004-2007).

${ }^{30}$ La composición de la Cámara de Diputados se modificó en las elecciones de 2006, de forma que el partido del presidente electo (PAN) recuperó curules (de 30\% que tenía en la legislatura LIX pasó a $41 \%$ en la Legislatura LX). 
En la gráfica $\mathrm{v}$ se muestran diferencias entre las iniciativas presidenciales y el ejercicio del gasto que remiten a un sobreejercicio presupuestario. Por ejemplo, para 2005 se aprobó un presupuesto de 381,332.9 millones de pesos a precios de 1993, no obstante se realizó un gasto de 415,171.8 millones de pesos, es decir, se gastaron 33,838.95 millones de pesos $(+8.9 \%)$ más de lo aprobado. Lo mismo sucedió para el 2006, con una diferencia por sobreejercicio de 54,291.03 millones de pesos. Esta expansión del gasto antes de las elecciones se podría considerar una evidencia de un comportamiento oportunista por parte del Ejecutivo.

Así, desde la esfera de la aprobación del presupuesto se gestó el ciclo político presupuestario para el periodo 2004-2007; es decir, el gobierno tuvo la oportunidad para ejercer el gasto de acuerdo con lo predicho por la teoría del CPP. Aún más, el gobierno federal no sólo tuvo la oportunidad sino que tuvo los incentivos para gastar más. Al observar la tasa de crecimiento real del presupuesto ejercido, éste muestra evidencia de CPP, aunque sólo con respecto el comportamiento previo a las elecciones, pues aunque en 2007 se presenta una tasa de crecimiento menor a la de 2005 y 2006, ésta no es negativa, es decir, no hay una contracción del gasto posterior a las elecciones, por lo que el CPP no se completa (gráfica v).

Aunque es difícil establecer las causas precisas con la información presentada hasta ahora, es posible, sin embargo, establecer como hipótesis explicativa que la recomposición de la Cámara permitió a más actores adoptar una conducta oportunista antes de las elecciones; es decir, el mayor gasto público no solamente lo ejerció el Ejecutivo, sino también los gobiernos estatales, muchos de los cuales pertenecían a partidos distintos al del presidente de la República y, por tanto, apoyaban a candidatos diferentes. Por su parte, aunque el crecimiento posterior a las elecciones es más difícil de explicar, dado que en los años previos se había tenido déficits fiscales, se puede pensar que la nueva mayoría relativa panista en la Cámara de Diputados aprobaba un gasto público mayor para impulsar las políticas del presidente Calderón, perteneciente al mismo partido, a lo cual no se opusieron los demás partidos de oposición, sobre todo el PRI y el PRD, dado que ellos también podrían disfrutar de ese mayor gasto. Adicionalmente, la visión que se tenía del déficit fiscal pudo haberse relajado un poco, en comparación con la exigencia que se tenía hasta mediados de los años noventa, cuando se pensaba que las cuentas públicas debían estar permanentemente en equilibrio; ${ }^{31}$ sin embargo, son necesarias más investigaciones para aclarar esta cuestión.

${ }^{31}$ Durante el periodo 2004-2007 los balances económicos presentaron déficits de 133,494, 129,060, 217,624 y 251,984 millones de pesos a precios de 2010, respectivamente (Banxico, 2011). 
Finalmente, durante los gobiernos sin mayoría la Cámara de Diputados ha realizado una función más activa en el procedimiento legislativo; ha llevado a cabo reasignaciones significativas del presupuesto, alejándose de la política de suma cero; ha reactivado los mecanismos de pesos y contrapesos entre ambos poderes. Sin embargo, esto es una limitante parcial para la generación del CPP debido a que el resultado de las modificaciones no refleja un gasto limitado que inhiba su ejercicio. Hay evidencia de un comportamiento oportunista antes de las elecciones de 2006; no obstante, no se presenta la contracción posterior sugerida por la teoría del CPP.

\section{Conclusiones}

Sour et al. (2004) realizaron una investigación donde muestran, con base en el número de ramos modificados y en las reasignaciones, cómo la participación de la Cámara de Diputados ha ido creciendo durante las Legislaturas LVII y LVIII (1997-2003). Al comparar la participación en el proceso presupuestario, se observó que la segunda hizo más modificaciones, tanto en el monto de los recursos redistribuidos como en el número de ramos modificados. Esta evolución muestra que el papel de la Cámara ha sido netamente más participativo en la negociación del presupuesto de egresos federales.

El presente trabajo evidencia que la composición de la Cámara de Diputados como contrapeso del Ejecutivo federal en lo que respecta al presupuesto, ha resultado sólo parcialmente eficaz para contrarrestar comportamientos oportunistas previstos por la teoría. La ejecución del gasto público en ambos periodos supone cierta evidencia de CPP, si bien es necesario resaltar algunas diferencias.

En 1994 es claro el amplio control sobre la aprobación del presupuesto por parte del Ejecutivo, lo cual parece haber favorecido el ejercicio del gasto público con fines electorales. Así, por un lado, se hizo evidente el cambio de politica fiscal instrumentado antes de las elecciones mediante la expansión del gasto público y, por otro, el intento de corregir las consecuencias de la política aplicada por medio de la contracción del gasto después de celebrados los comicios, aunque esta caída se manifestó de manera exacerbada por la recesión de 1995.

En el año 2006 la composición de la Cámara de Diputados tuvo su mayor efecto en el aumento de enmiendas realizadas al PPEF. Sin embargo, el gobierno dividido no eliminó la posibilidad de comportamientos oportunistas previstos por los modelos. Más aún, las modificaciones realizadas al PPEF significaron invariablemente una ampliación y no una restricción en términos de gasto, lo cual avala sólo una parte del CPP, eso 
es, la conducta oportunista previa a la elección y no el comportamiento posterior, pues no se presenta la contracción en el ejercicio del gasto.

Respecto a la fiscalización del gasto, los estudios realizados en México coinciden en la ausencia o supervisión insuficiente en la ejecución de éste (Magaloni y Díaz-Cayeros, 1998; Ugalde 2000; Casar, 2001). Block (2003) señala que en países donde existen escasos controles sobre las cuentas de gasto de gobierno es más notoria la presencia de ciclos políticos. Al respecto, Magaloni y Díaz-Cayeros (1998) sustentan que la Ley de Presupuesto y Gasto Público permitía al Ejecutivo realizar modificaciones al presupuesto (ampliaciones o reducciones) con la sola autorización de la Secretaría de Hacienda y Crédito Público. Por su parte, Ugalde (2000) indica que entre los factores más importantes para la limitada fiscalización legislativa se encuentran las motivaciones y el perfil de los diputados. Por ello, valdría la pena preguntarse si la falta de fiscalización en el ejercicio del gasto es un determinante para la presencia de CPP.

El alcance de esta investigación fue comprobar empíricamente la existencia de los ciclos políticos presupuestarios desde el ámbito del gobierno federal; queda por demostrar la gestación de éstos en las entidades federativas, promovidos por el creciente presupuesto público federal transferido a favor de los gobiernos subnacionales, que lo ejercen con una casi inexistente fiscalización y rendición de cuentas a la federación o sus congresos locales; en términos de Aguilar (2010), utilizan estas transferencias de dinero federal, entre otras cosas, para aceitar la política local. Asimismo, se puede retomar el análisis de los ciclos políticos presupuestarios tomando como variable instrumental los programas presupuestarios sensibles a la actividad electoral de los partidos políticos, como los que conforman el gasto en desarrollo social. 


\section{Anexo I}

\section{Modificaciones realizadas al Proyecto de Presupuesto de Egresos de la Federación, 2004-2007 (millones de pesos a precios constantes de 1993)}

\begin{tabular}{|c|c|c|c|c|}
\hline Ramos/año & 2004 & 2005 & 2006 & 2007 \\
\hline 01 Poder Legislativo & -380.39 & -48.3 & -170.49 & -174.8 \\
\hline 02 Presidencia de la República & -8.84 & -45.4 & -1.34 & 0 \\
\hline 03 Poder Judicial & -968.14 & -1153.38 & -1034.06 & -815.22 \\
\hline 04 Gobernación & -21.22 & -122.97 & 61.24 & -16.2 \\
\hline 05 Relaciones Exteriores & -16.37 & -95.42 & -3.97 & -12.37 \\
\hline 06 Hacienda y Crédito Público & -108.15 & 657.91 & 251.86 & 774.13 \\
\hline 07 Defensa Nacional & -65.55 & -171.45 & 140.5 & -19.45 \\
\hline $\begin{array}{l}08 \text { Agricultura, Ganadería, Desarro- } \\
\text { llo Rural, Pesca y Alimentación }\end{array}$ & -168.04 & 2360.27 & 2717.96 & 2046.37 \\
\hline 09 Comunicaciones y Transportes & 1455.34 & 3500.25 & 2721.71 & 2257.07 \\
\hline 10 Economía & -21.64 & 311.48 & 177.26 & 269.21 \\
\hline 11 Educación Pública & 847.56 & 1589.18 & 2429.05 & 1858.89 \\
\hline 12 Salud & -99.47 & 957.99 & 649.63 & 218.48 \\
\hline 13 Marina & -3.83 & -58.57 & 16.44 & -29.17 \\
\hline 14 Trabajo y Previsión Social & -72.6 & -11.72 & -0.06 & -9.72 \\
\hline 15 Reforma Agraria & -11.08 & 418.66 & 314.49 & 143.44 \\
\hline $\begin{array}{l}16 \text { Medio Ambiente y Recursos } \\
\text { Naturales }\end{array}$ & 150.92 & 1578.09 & 870.07 & 1292.29 \\
\hline $\begin{array}{l}17 \text { Procuraduría General } \\
\text { de la República }\end{array}$ & -25.25 & -120.14 & 12.89 & 0 \\
\hline 18 Energía & -4.07 & 12.31 & -1.38 & 13.03 \\
\hline 19 Aportaciones a Seguridad Social & -63.85 & -629.12 & -4953.96 & 0 \\
\hline 20 Desarrollo Social & 480.51 & 358.53 & 17.38 & 1455.32 \\
\hline 21 Turismo & -13.54 & -17.24 & -0.7 & 14.59 \\
\hline 22 Instituto Federal Electoral & -71 & 41.94 & -206.43 & -140.08 \\
\hline $\begin{array}{l}23 \text { Provisiones Salariales } \\
\text { y Económicas }\end{array}$ & 2379.8 & -0.27 & 953.42 & -3375.13 \\
\hline 24 Deuda Pública & 0 & 0 & -301.07 & -778 \\
\hline $\begin{array}{l}25 \text { Previsiones y Aportaciones para } \\
\text { los Sistemas de Educación } \\
\text { Básica, Normal y Tecnológica } \\
\text { y de Adultos }\end{array}$ & 600.75 & 1341.38 & 867.49 & 685.38 \\
\hline 27 Función Pública & -40.03 & -8.68 & -1.65 & 0 \\
\hline $\begin{array}{l}28 \text { Participaciones a Entidades } \\
\text { Federativas y Municipios }\end{array}$ & 542.89 & 1658.75 & 1602.32 & 943.6 \\
\hline
\end{tabular}


Continúa Anexo I...

\begin{tabular}{|c|c|c|c|c|}
\hline Ramoslaño & 2004 & 2005 & 2006 & 2007 \\
\hline 30 Adeudos de Ejercicios Fiscales & & & & \\
\hline Anteriores & -841.83 & -1415.51 & -325.8 & -778 \\
\hline 31 Tribunales Agrarios & 0 & 18.24 & -0.72 & 38.9 \\
\hline $\begin{array}{l}32 \text { Tribunal Federal de Justicia Fiscal } \\
\text { y Administrativa }\end{array}$ & -7.67 & 35.75 & -1.28 & 9.73 \\
\hline $\begin{array}{l}33 \text { Aportaciones Federales para } \\
\text { Entidades Federativas } \\
\text { y Municipios }\end{array}$ & 141.48 & 577.85 & 615.45 & 3971.93 \\
\hline $\begin{array}{l}34 \text { Erogaciones para los Programas } \\
\text { de Apoyo a Ahorradores } \\
\text { y Deudores de la Banca }\end{array}$ & -664.6 & -1258.23 & 0 & 0 \\
\hline $\begin{array}{l}35 \text { Comisión Nacional de los } \\
\text { Derechos Humanos }\end{array}$ & -5.14 & 0.99 & -24.79 & -36.9 \\
\hline 36 Seguridad Pública & -56.91 & 24.6 & 103.01 & -291.75 \\
\hline $\begin{array}{l}37 \text { Consejería Jurídica del Ejecutivo } \\
\text { Federal }\end{array}$ & -5.27 & -0.38 & -0.1 & -2.24 \\
\hline $\begin{array}{l}38 \text { Consejo Nacional de Ciencia } \\
\text { y Tecnología }\end{array}$ & 74.21 & 261.88 & 196.74 & 0 \\
\hline $\begin{array}{l}39 \text { Programa de Apoyo para el } \\
\text { Fortalecimiento de las Entidades } \\
\text { Federativas }\end{array}$ & 1550.73 & 4275.05 & 4516.08 & I \\
\hline $\begin{array}{l}\text { Entidades sujetas a control } \\
\text { presupuestario directo }\end{array}$ & -1498.5 & 343.39 & 6494.62 & -1064.69 \\
\hline
\end{tabular}

Fuente: Elaboración Propia con datos de la SHCP (2004-2007). 


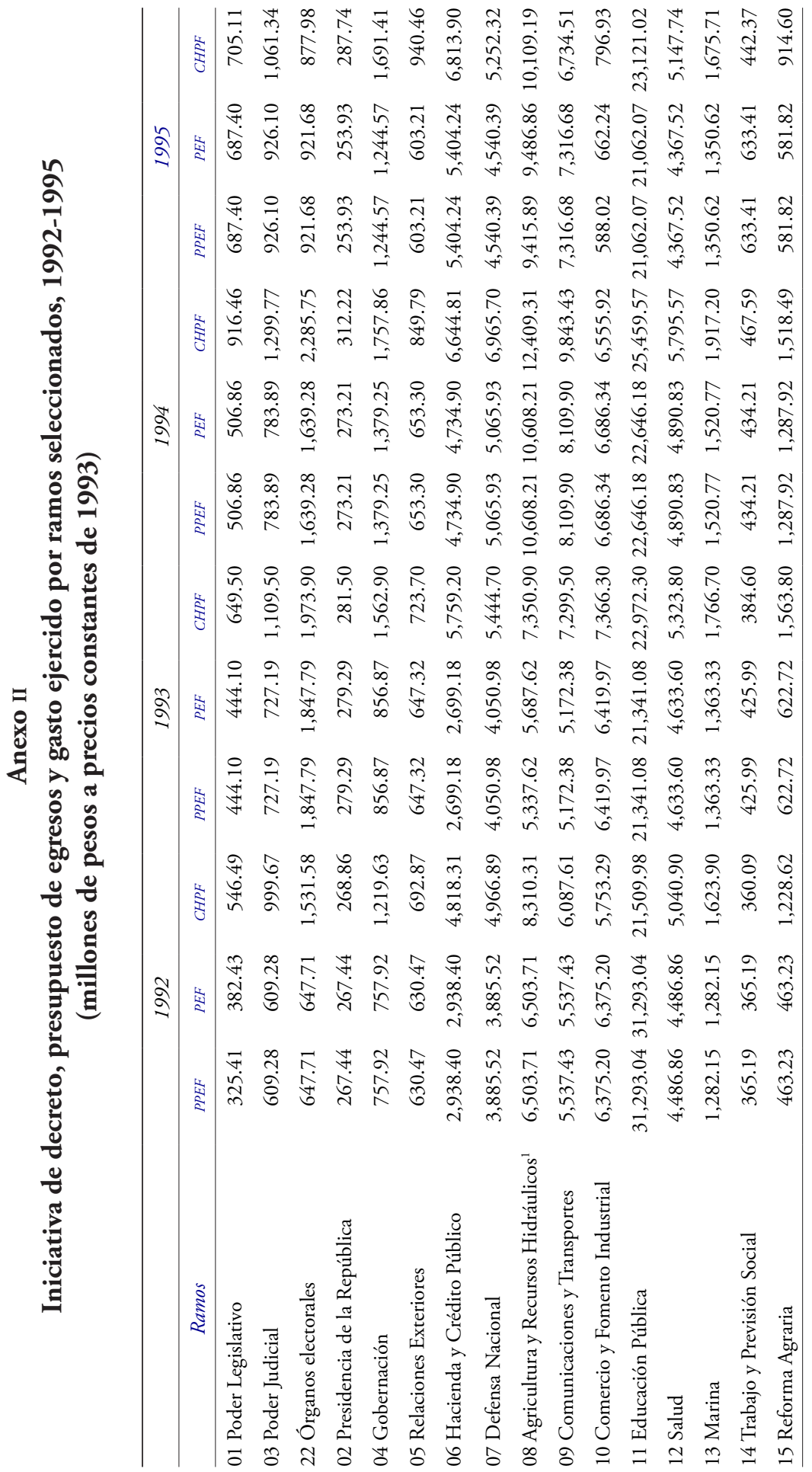




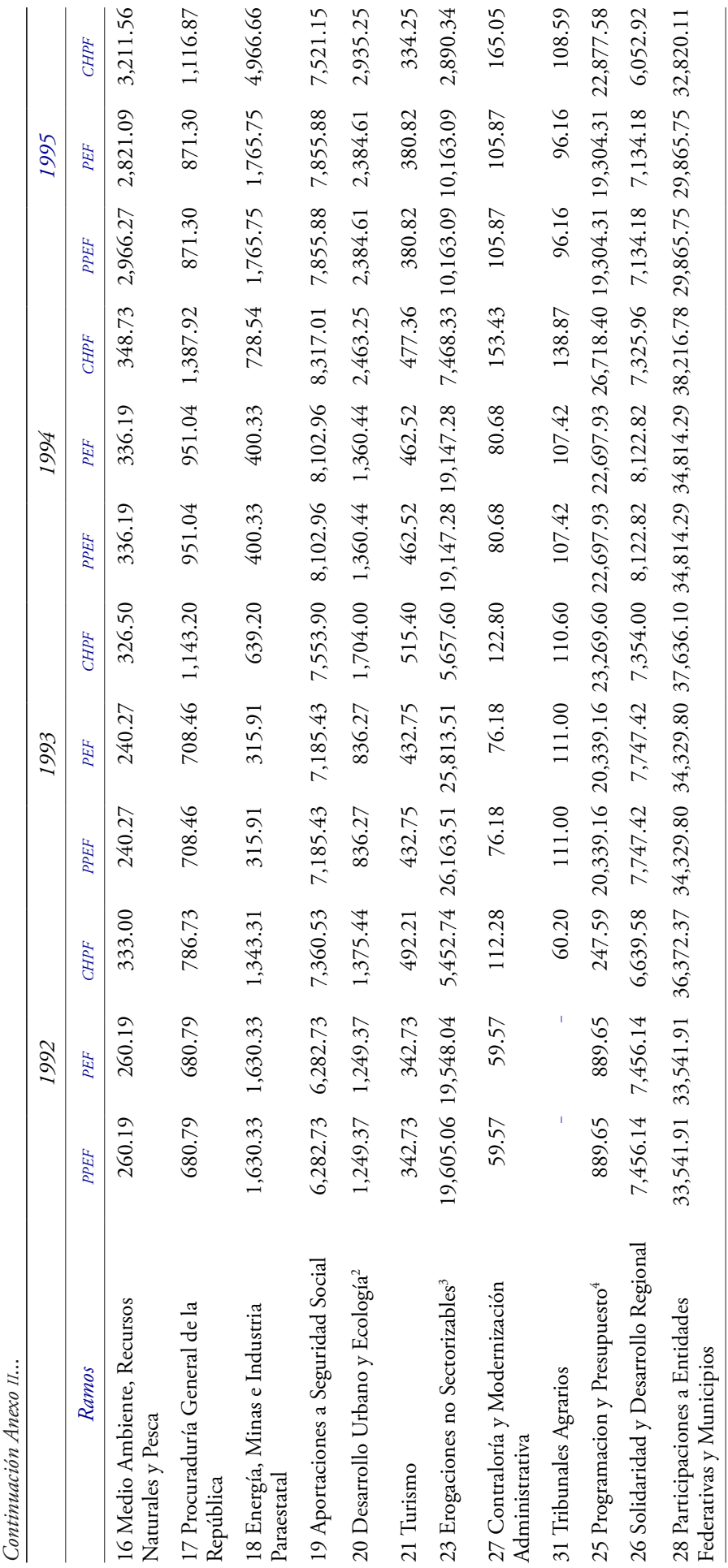




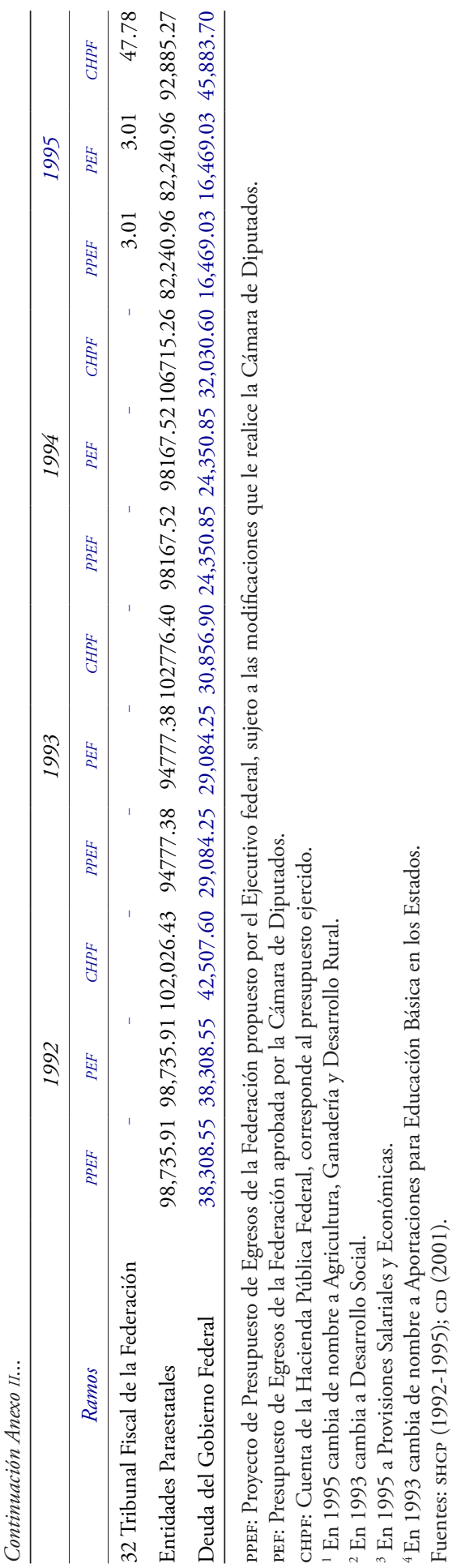




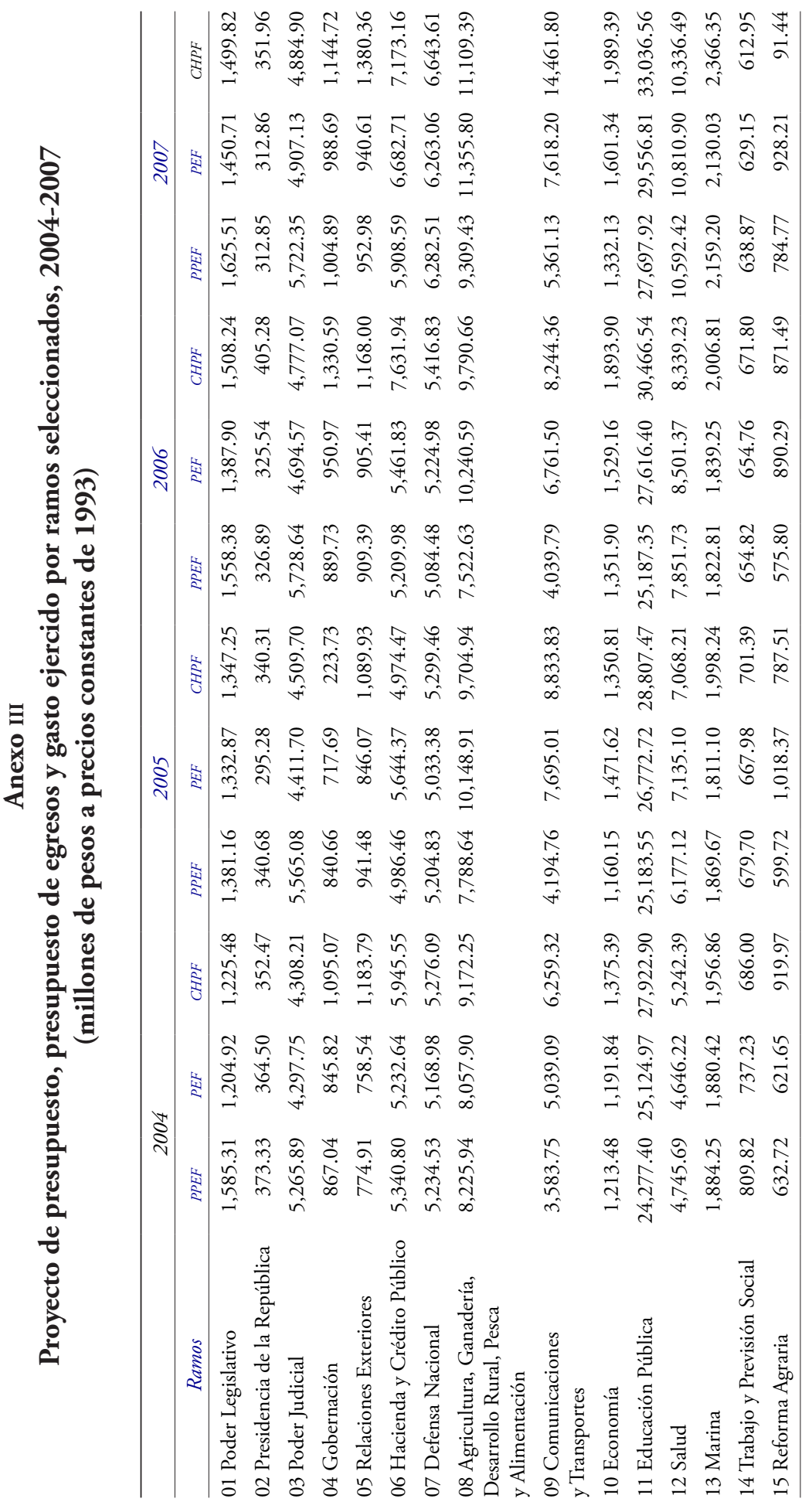




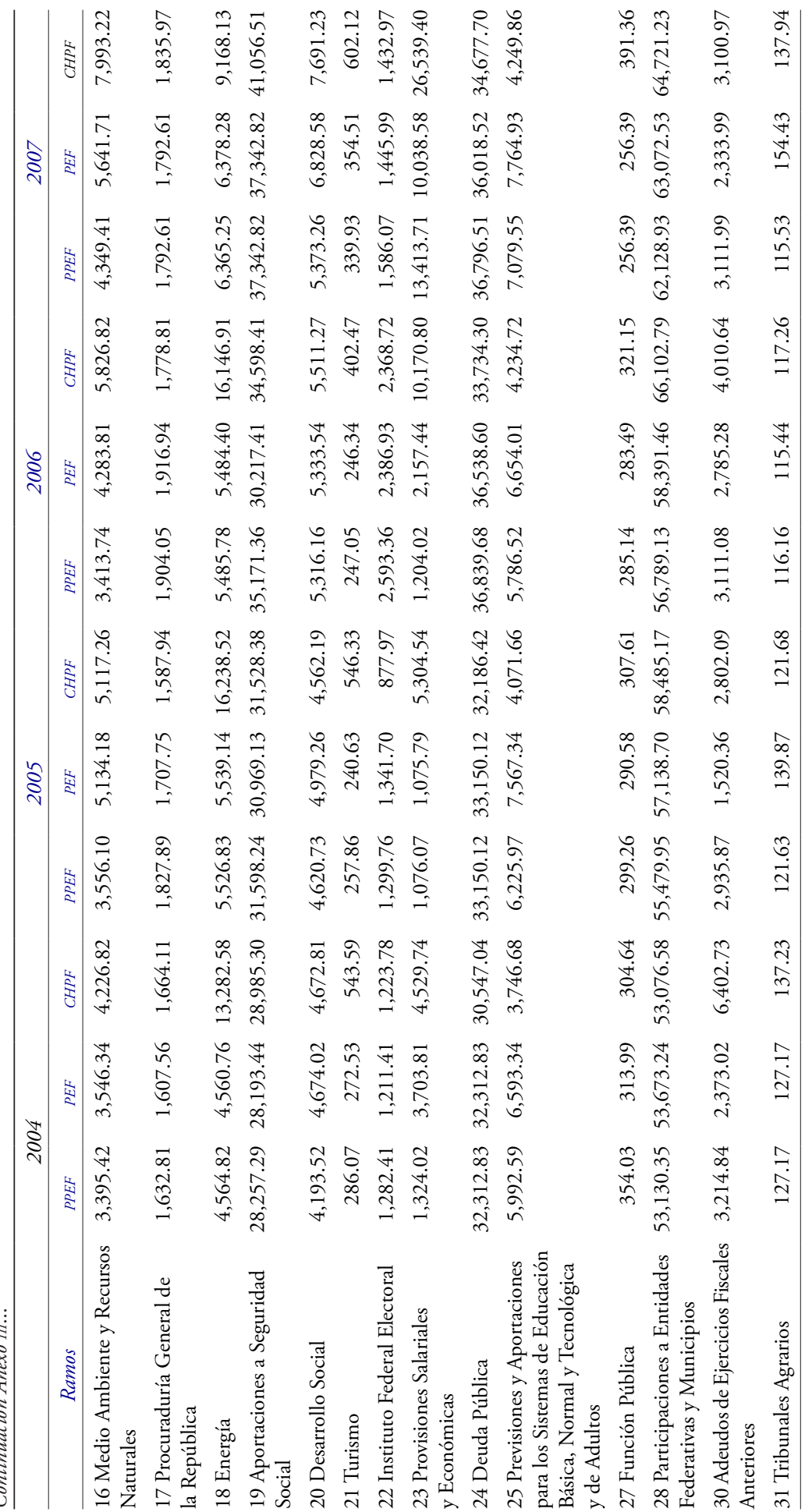




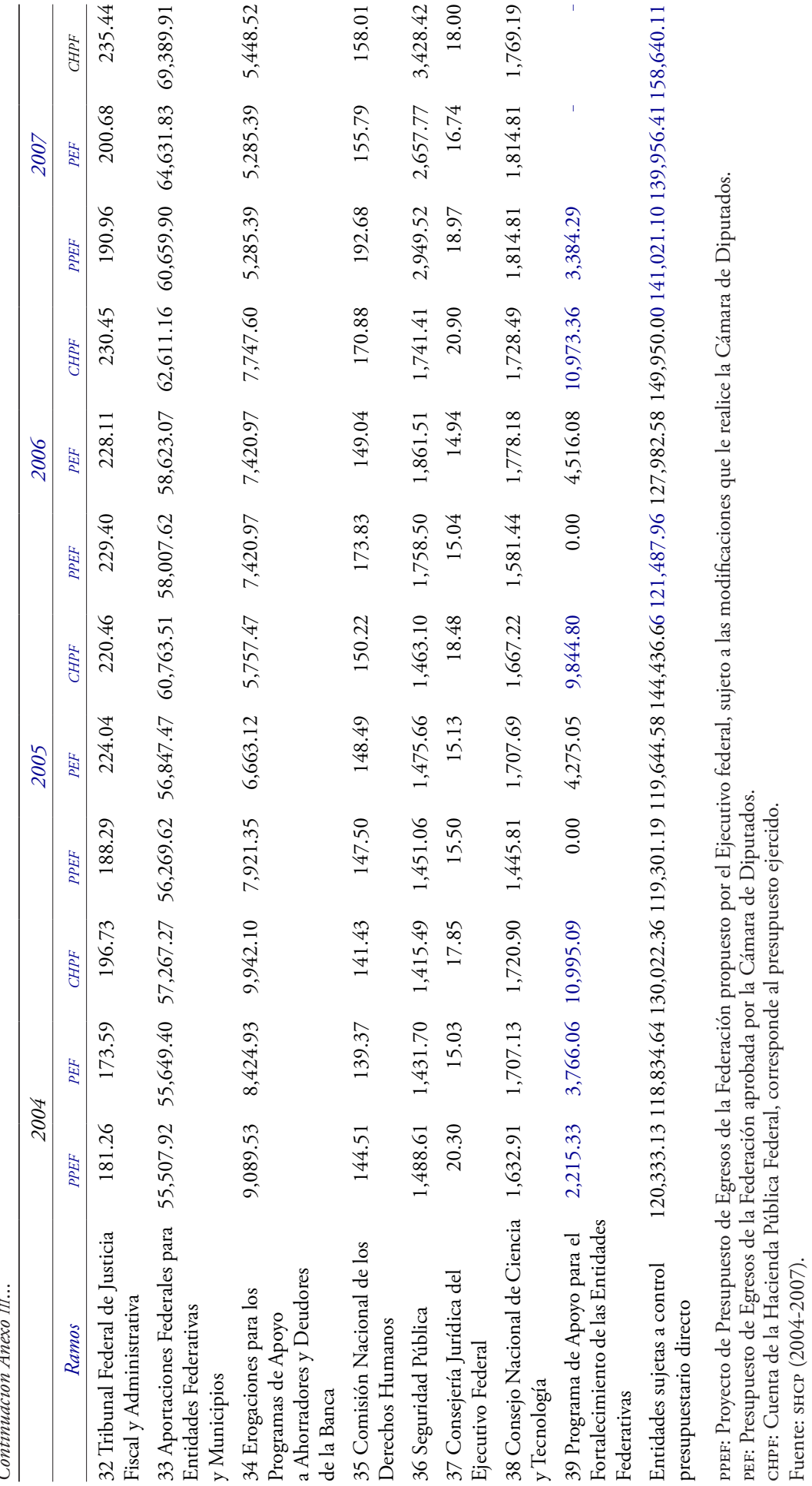




\section{Bibliografía}

Aguilar, Héctor (2010), "Feudalismo: la democracia desigual", en Milenio Diario, 2 de febrero, México, p. 2.

Argandoña, Antonio (1996), Macroeconomía avanzada, modelos dinámicos y teoría de la política económica, McGraw Hill, Madrid.

Alesina, Alberto (1989), "Politics and business cycles in industrial democracies", Economic Policy, 8, Blackwell Publishing, New Jersey, pp. 55-98.

Alesina, Alberto, Nouriel Roubini y Gerald Cohen (1992), "Macroeconomic policy and elections in OECD democracies", Centre for Economic Policy Research, Discussion Paper, núm. 608.

Alesina, Alberto, Nouriel Roubini y Gerald Cohen (1997), Political Cycles and the Macroeconomy, The MIт Press, Cambridge.

вм (Banco de México) (1995), Informes anuales, Banco de México, México.

Banxico (2011), <http://www.banxico.org.mx/SieInternet/consultarDirectorioInternetAction.do?accion $=$ consultarCuadro\&idCuadro $=$ CG2\&sector=9\&locale=es $>, 23$ de noviembre de 2011.

Block, Steven (2003), "Elections and the composition of public spending in developing countries", Fletcher School of Law and Diplomacy, Tufts University, Working Paper, núm. 78.

Borsani, Hugo (2003), "Elecciones, gobiernos mayoritarios y resultados macroeconómicos en América Latina (1999-1998)”, Desarrollo Económico, 43 (171), Instituto de Desarrollo Económico y Social, Buenos Aires, pp. 389-412.

CD (Cámara de Diputados, H. Congreso de la Unión) (2001), Evolución y estadísticas del gasto público federal en México, 1980-2001, Centro de Estudios de las Finanzas Públicas, Cámara de Diputados, México. 
CD (Cámara de Diputados, H. Congreso de la Unión) (2005), "Reformas a la ley federal electoral: los diputados de partido", Cámara de Diputados, México.

CD (Cámara de Diputados, H. Congreso de la Unión) (2009), “Comparativo del Ramo 23 Provisiones Salariales y Económicas", nota informativa notacefp/093/2009, Centro de Estudios de las Finanzas Públicas, Cámara de Diputados, México.

Cárdenas, Enrique (1996), La politica económica de México 1950-1994, Fondo de Cultura Económica, México.

Casar, María Amparo (2001), "El proceso de negociación presupuestal en el primer gobierno sin mayoría: un estudio de caso", Programa de Presupuesto y Gasto Público del Cide y Fundación Ford, Documento de trabajo núm. 137, México.

Derechos del pueblo mexicano. México a través de sus constituciones (2006), vol. xviII, Cámara de Diputados-Senado de la República-Poder Judicial de la Federación-Miguel Ángel Porrúa, México.

Diario Oficial de la Federación (1991), 24 de diciembre, México.

Diario Oficial de la Federación (1992), 18 de diciembre, México.

Diario Oficial de la Federación (1993), 30 de diciembre, México.

Diario Oficial de la Federación (1994), 28 de diciembre, México.

Diario Oficial de la Federación (2003), 31 de diciembre, México.

Diario Oficial de la Federación (2004), 20 de diciembre, México.

Diario Oficial de la Federación (2005), 22 de diciembre, México.

Diario Oficial de la Federación (2006), 28 de diciembre, México.

Drazen, Allan (2001), "The political business cycle after 25 years", en Ben Bernanke y Kenneth Rogoff (eds.), NBER Macroeconomics Annual 2000, 15, The мiт Press, Cambridge, pp. 75-138. 
Gámez, Cesáreo (2010), El ciclo político y la economía mexicana, Universidad Autónoma de Nuevo León, Monterrey.

Gámez, Cesáreo y Alejandro Ibarra-Yúnez (2009), "El ciclo político oportunista y el gasto de los estados mexicanos", Gestión y Politica Pública, XviII (1), Centro de Investigación y Docencia Económicas, México, pp. 39-65.

Gámez, Cesáreo y Jaime Botello (1987), "La influencia del ciclo presidencial en la economía mexicana: un ejercicio econométrico con variables dummy", en Jesús Lechuga (coord.), El dilema de la economía mexicana: Ensayos de interpretación, Ediciones de Cultura Popular-Universidad Autónoma Metropolitana, México, pp. 215-232.

González, María de los Ángeles (2002), "Do changes in democracy affect the political budget cycle? Evidence from México", Review of Development Economics, 6 (2), Wiley-Blackwell-Iowa State University, pp. 204-224.

Heath, Jonathan (2000), La maldición de las crisis sexenales, Iberoamérica, México.

Hibbes, Douglas (1977), "Political Parties and Macroeconomic Policy", American Political Science Review, 71, Cambridge University Press-American Political Science Association, Cambridge, pp. 1466-1487.

Kalecki, Michal (1943), "Political aspects of full employment", Political Quarterly, 7, Wiley-Blackwell-Iowa State University, pp. 322-331.

Lustig, Nora (2002), México hacia la reconstrucción de una economía, Fondo de Cultura Económica, México.

Magaloni, Beatriz (2000), "Institutions, Political Opportunism and Macroeconomic Cycles: México 1970-1998”, conferencia Instituciones políticas y económicas. El crecimiento en América Latina: conferencia de las ciencias sociales del Instituto de Historia de la Universidad de Stanford, Stanford University.

Magaloni, Beatriz y Alberto Díaz-Cayeros (1998), "Autoridad presupuestal del Poder Legislativo en México: una primera aproximación”, 
Política y Gobierno, v (2), Centro de Investigación y Docencia Económicas, México, pp. 503-528.

Muñoz, Rafael (2006), "Ciclos político económicos: teoría y evidencia empírica”, Temas de Coyuntura, 54, Universidad Católica Andrés Bello, Caracas, pp. 29-72.

Nordhaus, William (1975), "The political business cycle", Review of Economic Studies, 42, Oxford University Press, Oxford, pp. 169190.

OCDE (Organización para la Cooperación y el Desarrollo Económico) (2009), "OECD Review of Budgeting in Mexico", OECD Journal on Budgeting, Supplement 1, París.

Ortega, Juan Manuel (2006), "Acuerdos tripartitas y gobernanza económica en el México de fin de siglo", Foro Internacional, xLVI (2), El Colegio de México, México, pp. 227-262.

Pichardo, Ignacio (1981), México: reflexiones sobre el proceso presupuestal en la Cámara de Diputados. Un enfoque comparativo, Instituto Nacional de Administración Pública, México.

Presidencia de la República (1991), Iniciativa de Decreto, 15 de noviembre, México.

Presidencia de la República (1992), Iniciativa de Decreto, 10 de noviembre, México.

Presidencia de la República (1993), Iniciativa de Decreto, 15 de noviembre, México.

Presidencia de la República (1994a), Iniciativa de Decreto, 9 de diciembre, México.

Presidencia de la República (1994b), Criterios generales de política económica para la iniciativa de ley de ingresos y el proyecto de presupuesto de egresos de la federación correspondientes a 1995, México, pp. 15-18.

Presidencia de la República (2009), Anexo del Tercer Informe de Gobierno, México. 
Sartori, Giovanni (1980), Partidos y sistemas de partidos, Alianza, Madrid.

Shi, Min y Jakob Svensson (2002), "Conditional political budget cycles", CEPR Discussion Paper, núm. 3352.

Schuknecht, Ludger (1996), "Political business cycles and fiscal policies in developing countries”, Kyklos, 49 (2), International Review for Social Sciences, Basilea, pp. 155-170.

Schumpeter, Joseph (1939), Business Cycles: A Theoretical, Historical, and Statistical Analysis of the Capitalist Process, McGraw Hill, Nueva York.

scjn (Suprema Corte de Justicia de la Nación) (2005), Controversia Constitucional 109/2004 relacionada con la facultad que tiene el titular del Poder Legislativo para hacer observaciones al presupuesto de Egresos de la Federación, Oficio núm. 2193, Subsecretaría General de Acuerdos, 27 de mayo, México.

ShCP (Secretaría de Hacienda y Crédito Público) (2004), Decreto de Presupuesto de Egresos de la Federación, México.

SHCP (Secretaría de Hacienda y Crédito Público (2005), El Presupuesto de Egresos de la Federación, México.

SHCP (Secretaría de Hacienda y Crédito Público) (2006), El Proyecto de Presupuesto de Egresos de la Federación, México.

SHCP (Secretaría de Hacienda y Crédito Público) (2007), La Cuenta de la Hacienda Pública Federal, México.

SHCP (Secretaría de Hacienda y Crédito Público) (2000), El Presupuesto de Egresos de la Federación 1995-2000, sHCP, Subsecretaría de Egresos, México.

Sour, Laura, Irma Ortega y Sergio San Sebastián (2004), "Política presupuestaria durante la transición a la democracia en México: 19972003”, Documento de Trabajo núm. 142, Centro de Investigación y Docencia Económicas, México.

Stein, Ernesto, Mariano Tommasi, Koldo Echebarría y Eduardo Lora (2006), La politica de las políticas públicas. Informe 2006, PlanetaBanco Interamericano de Desarrollo, Nueva York. 
Tufte, Edward (1978), Political Control of the Economy, Princeton University Press, Princeton.

Ugalde, Luis Carlos (1997), "Los aspectos legislativos del gasto público en México", Perfiles Latinoamericanos, 10, flacso, México, pp. 75-99.

Ugalde, Luis Carlos (2000), Vigilando al Ejecutivo. El papel del Congreso en la supervisión del gasto público, Porrúa, México.

Velázquez, Rafael (2008), "La relación entre el Ejecutivo y el Congreso en materia de política exterior durante el sexenio de Vicente Fox: ¿cooperación o conflicto?”, Política y Gobierno, xv (1), Centro de Investigación y Docencia Económicas, México, pp. 113-157.

Valdés, Leonardo (1988), "Nueva ley electoral y democracia: algunos avances, muchos retrocesos", Iztapalapa, 8 (15), Universidad Autónoma Metropolitana, México, pp. 135-150.

Weldon, Jeffrey (1997), "The Political Sources of Presidencialismo in México", en Scott Mainwaring y M. Soberg Shugart (eds.), Presidentialism and Democracy in Latin America, Cambridge University Press, pp. 225-257.

Recibido: 27 de septiembre de 2011. Reenviado: 13 de enero de 2012. Aceptado: 1 de febrero de 2012.

Marlen R. Reyes-Hernández. Es maestra en economía por la Facultad de Economía de la Universidad Autónoma del Estado de México (UAEM). Egresada del Doctorado en Ciencias Económico-Administrativas de la Facultad de Economía y la Facultad de Contaduría y Administración de la UAEM. Actualmente es profesora-investigadora del Campus Universitario Siglo XXI. Su línea de investigación es: ciclo político presupuestal y política fiscal.

Pablo Mejía-Reyes. Es doctor en economía por la Universidad de Manchester, Reino Unido. Es profesor-investigador de la Facultad de Economía de la Universidad Autónoma del Estado de México (UAEM). Sus líneas de investigación actuales son: fluctuaciones cíclicas e integración económica internacional. Entre sus publicaciones sobresalen: en coautoría, "Are 
the Mexican states and the United States business cycles synchronised? Evidence from the manufacturing production", Economía Mexicana, nueva época, xx (1), CIDE, México, pp. 79-112 (2011); "Sincronización nacional e internacional de la manufactura de los estados de México", en P. Mejía Reyes y M. E. Morales Fajardo (coords.), Integración y recesión económica en el binomio México-Estados Unidos, UaEM, Toluca, pp. 211240 (2011); en coautoría, "Modelling real exchange rate effects of output performance in Latin America”, Applied Economics, 42, (19), Taylor \& Francis, Londres pp. 2491-2503 (2010); en coautoría, "Looking for asymmetries over the Mexican business cycle", Investigación Económica, LXIX (271), unam, México, pp. 15-42 (2010).

Paolo Riguzzi. Es doctor en historia por la Universidad de Génova. Profesor-investigador de El Colegio Mexiquense, A.C. Línea de investigación actual: la banca extranjera en México, 1900-1950, y los presupuestos federales mexicanos, 1896-1929. Entre sus publicaciones sobresalen: "El ciclo de vida de la banca británica en México, 1863-1933", Revista de Historia de la Economía y la Empresa, Madrid, en prensa (2012); en coautoría, "Borders, Trade and Politics: Exchange between the U.S. and Mexican Cattle Industries, 1870-1947”, Hispanic American Historical Review, en prensa (2012); "From Globalization to Revolution? The Porfirian Political Economy, an Essay on Issues and Interpretations", Journal of Latin American Studies, 41 (2), Cambridge University Press, Cambridge, pp. 347-368. 